Originally published as:

Uchanska-Ziegler, B., Loll, B., Fabian, H., Hee, C.S., Saenger, W., Ziegler, A.

HLA class l-associated diseases with a suspected autoimmune etiology: HLA-B27 subtypes as a model system

(2012) European Journal of Cell Biology, 91 (4), pp. 274-286.

DOI: $10.1016 / \mathrm{j} . \mathrm{ejcb} .2011 .03 .003$

This is an author manuscript.

The definitive version is available at: http://www.sciencedirect.com/ 


\title{
HLA class I-associated diseases with a suspected autoimmune etiology: HLA-B27 subtypes as a model system
}

\author{
Barbara Uchanska-Ziegler ${ }^{\mathrm{a}}$, Bernhard Loll ${ }^{\mathrm{b}}$, Heinz Fabian ${ }^{\mathrm{c}}$, Chee Seng Hee ${ }^{\mathrm{a}}$, Wolfram Saenger ${ }^{\mathrm{d}}$, \\ Andreas Ziegler ${ }^{\mathrm{a}}$ \\ a Institut für Immungenetik, Charité - Universitätmedizin Berlin, Campus Benjamin Franklin, Freie \\ Universität Berlin, Thielallee 73, 14195 Berlin, Germany \\ ${ }^{\mathrm{b}}$ Institut für Chemie und Biochemie, Abteilung Strukturbiochemie, Freie Universität Berlin, \\ Takustrasse 6, 14195 Berlin, Germany \\ ${ }^{\mathrm{c}}$ Robert Koch-Institut, P 25, Nordufer 20, 13353 Berlin, Germany \\ ${ }^{d}$ Institut für Chemie und Biochemie, Abteilung Kristallographie, Freie Universität Berlin, Takustrasse 6, \\ 14195 Berlin, Germany
}

\begin{abstract}
Although most autoimmune diseases are connected to major histocompatibility complex (MHC) class II alleles, a small number of these disorders exhibit a variable degree of association with selected MHC class I genes, like certain human HLA-A and HLA-B alleles. The basis for these associations, however, has so far remained elusive. An understanding might be obtained by comparing functional, biochemical, and biophysical properties of alleles that are minimally distinct from each other, but are nevertheless differentially associated to a given disease, like the HLA-B*27:05 and HLA-B*27:09 antigens, which differ only by a single amino acid residue (Asp116His) that is deeply buried within the binding groove. We have employed a number of approaches, including $X$-ray crystallography and isotope-edited infrared spectroscopy, to investigate biophysical characteristics of the two HLA-B27 subtypes complexed with up to ten different peptides. Our findings demonstrate that the binding of these peptides as well as the conformational flexibility of the subtypes is greatly influenced by interactions of the $C$-terminal peptide residue. In particular, a basic $C$-terminal peptide residue is favoured by the disease-associated subtype $H L A-B^{*} 27: 05$, but not by $H L A-B{ }^{*} 27: 09$. This property appears also as the only common denominator of distinct HLA class I alleles, among them HLA$\mathrm{B}^{*}$ 27:05, HLA-A*03:01 or HLA-A*11:01, that are associated with diseases suspected to have an autoimmune etiology. We postulate here that the products of these alleles, due to their unusual ability to bind with high affinity to a particular peptide set during positive $T$ cell selection in the thymus, are involved in shaping an abnormal $T$ cell repertoire which predisposes to the acquisition of autoimmune diseases.
\end{abstract}

\section{Introduction}

The major histocompatibility complex (MHC) of vertebrates occupies a central role within the immune system through its participation in innate and adaptive immune responses ( [Horton et al., 2004] and [Kelley et al., 2005]). However, due to its involvement in processes that rely on self/nonself perception, it exerts crucial functions also in mate selection and reproduction ( [Ziegler, 1997], [Ziegler, 2003], [Ziegler et al., 2000], [Ziegler et al., 2002], [Ziegler et al., 2005], [Ziegler et al., 2006], [Ziegler et al., 2010a], [Penn and Potts, 1998], [Ehlers et al., 2000], [Milinski, 2006] and [Piertney and Oliver, 2006]), as well as in neuronal communication ( [Huh et al., 2000], [Rölleke et al., 2006], [Goddard et al., 2007], [McConnell et al., 2009] and [Ribic et al., 2010]). In humans, the MHC, also termed the human leukocyte antigen (HLA) complex, is packed with hundreds of genes, making it the most genedense region within the genome, and some HLA loci are the most polymorphic human genes (Horton et al., 2004). For example, the HLA-A and HLA-B loci together boast more than $\sim 3000$ alleles 
(http://hla.alleles.org) whose products serve the promiscuous presentation of peptides (Fig. 1A) derived from foreign and self-proteins. This extreme polymorphism is an obvious nuisance in a transplant setting, as the combined polymorphism of just the $H L A-A$ and $H L A-B$ genes could result in millions of HLA haplotypes, making it very unlikely among unrelated individuals that a suitable organ donor might be found next door.

In addition, a multitude of loci encoding peptide-presenting molecules, although advantageous for the presentation of a maximal number of foreign peptides in the course of an infection, poses a threat for the integrity of the individual. Theoretical considerations have been used to argue that the chances of obtaining an autoimmune disease will tend to rise with an elevated number of loci encoding these polymorphic proteins, indicating that an intermediate number of distinct antigen-presenting molecules is best to assure not only an effective immune response, but also to minimize autoimmunity caused by T cells bearing cross-reactive T cell receptors (TCR) ( [Nowak et al., 1992] and [Mason, 1998]). Although the MHC architecture of several species appears to prove the validity of this concept ( [Milinski, 2006] and [Woelfing et al., 2009]), there is evidence that exceptions do exist. The chicken (Gallus gallus domesticus), for example, possesses only a single highly polymorphic "classical", i.e. peptide-presenting, MHC class I antigen ( [Ziegler and Pink, 1976], [Wallny et al., 2006] and [Koch et al., 2007]), but can acquire autoimmune diseases (see e.g. Sundick et al., 1996) despite this minimal genetic outfit. Nevertheless, the function of its immune system appears unimpaired, possibly due to the exceptional expansion of highly polymorphic loci encoding immunoglobulin-like receptors which we found in this species (Laun et al., 2006). Another polymorphic molecule (YF1) with a classical MHC class I scaffold might also contribute to the chicken's survival, although it presents lipids and not peptides and is encoded by a gene that is not part of the chicken MHC, the MHC-B region (Hee et al., 2010).

The possible consequences of carrying only MHC class I genes exhibiting a very low degree of polymorphism can be seen in the Tasmanian devil (Sarcophilus harrisii). The population of this carnivorous marsupial has declined by more than $50 \%$ due to the spread of a highly contagious clonal malignancy, devil facial tumour disease (McCallum, 2008), which is transmitted by biting during mating and competition for food. The tumour is not rejected, however, because its MHC antigens are nearly identical to those of the infected animals ( [Siddle et al., 2007] and [Siddle et al., 2010]).

There is evidence indicating that the HLA complex is associated with virtually all human autoimmune diseases ( [Horton et al., 2004] and [Fernando et al., 2008]). The vast majority of these are primarily associated with HLA class II loci, although other genes within as well as outside of the HLA complex may contribute to the susceptibility, as in Rheumatoid Arthritis or Multiple Sclerosis (MS) (Anaya, 2010). Some diseases with a suspected autoimmune etiology, however, are clearly associated with HLA class I, and not with class II loci. The first one for which such an association was discovered, and still that with the strongest, is Ankylosing Spondylitis (AS) ( [Brewerton et al., 1973] and [Schlosstein et al., 1973]). Individuals with the HLA-B27 allele have a greatly increased risk to acquire AS or another seronegative spondyloarthropathy such as Reactive Arthritis. In the case of AS, this risk is $\sim 90$ times higher and nearly all AS patients are positive for $H L A-B 27$, although the frequency of this allele in the Central European population is only $\sim 6 \%$. Epidemiological, clinical as well as molecular aspects of spondyloarthropathies and $H L A-B 27$ have recently been extensively reviewed in several articles in a book edited by López-Larrea and Díaz-Peña (2009).

One of the most promising developments in understanding AS and related disorders has been the detection of $H L A-B 27$ subtypes that are minimally distinct from each other. For example, the product of the $H L A-B^{*} 27: 05$ subtype (in short, $\left.B^{*} 27: 05\right)$ differs only by a single amino acid exchange (Asp116His) from that of the HLA-B*27:09 subtype (in short, $B^{\star 2} 27: 09$ ) (Fig. 1A) (D'Amato et al., 1995). Both subtypes are, however, differentially associated with AS: $B^{\star 27: 05-p o s i t i v e ~ i n d i v i d u a l s ~ c a n ~ a c q u i r e ~ t h e ~}$ disease, while $B^{*} 27: 09$ is not found to be associated. Similar findings have been made for the $B^{\star 27: 04 / B}$ 27:06 pair, in which two amino acid exchanges (His114Asp and Asp116Tyr) are observed ( [López de Castro, 2007] and [López de Castro et al., 2004]). In this case, $B^{\star 27: 04 ~ i s ~ A S-a s s o c i a t e d, ~}$ $B^{\star} 27: 06$ is not. Furthermore, a distantly related pair of $H L A-B$ alleles, $B^{*} 14: 02 / B^{\star} 14: 03$, appears also differentially associated to AS, but the exchange involves another residue (Leu156Arg) than in the case of the HLA-B27 pairs of subtypes ( [López-Larrea et al., 2002], [Díaz-Peña et al., 2008], [Kumar et al., 2007] and [Kumar et al., 2009a]). 
Collectively, the differential association of these pairs of alleles to AS, together with experiments involving $B^{\star 27: 05-t r a n s g e n i c ~ r a t s ~(r e v i e w e d ~ b y ~[T a u r o g, ~ 2009] ~ a n d ~[T a u r o g, ~ 2010]) ~ s u g g e s t ~ t h a t ~ t h e ~}$ encoded proteins, and not HLA-B27-linked genes, are responsible for these findings. These observations in transgenic animals are important as it is known for many years that linkage disequilibrium is one of the hallmarks of the HLA complex ( [Malfroy et al., 1997], [Horton et al., 2004] and [Fernando et al., 2008]). It tends to keep certain alleles together in one haplotype (Santos et al., 2010) and makes the assignment of disease-causing genes problematic (Santos et al., 2008). In addition, the situation in the case of HLA-B27-associated diseases is complicated by the fact that HLAunlinked genes ( [Australo-Anglo-American Spondyloarthritis Consortium, 2010] and [Thomas and Brown, 2010]) as well as environmental influences can modulate the disorder.

On the other hand, the existence of HLA subtypes that are distinguished only by micropolymorphisms but are nevertheless differentially associated with spondyloarthropathies suggested to us that it might be fruitful to investigate these subtypes with biophysical techniques including X-ray crystallography as well as isotope-edited infrared (IR) spectroscopy and to correlate the results, whenever possible, with functional studies. The results obtained so far by our group have led to several important insights. Using a monoclonal antibody (mAb) with peptide-dependent reactivity with HLA-B27 molecules, we could show that a subpopulation of $B^{\star} 27: 05$ molecules is able to bind not only conventional 8-10 residue long peptides, but also much longer ones with up to $\sim 30$ amino acids (Urban et al., 1994). We demonstrated also that mAb can be employed to distinguish structurally distinct forms of these molecules from each other ( [Heinrichs et al., 1980], [Müller et al., 1983], [Rehm et al., 2000], [Uchanska-Ziegler and Ziegler, 2007] and [Ziegler et al., 2007]), and we have contributed to assess the intracellular dynamics of HLA-B27 molecules as well (Dangoria et al., 2002).

Recent evidence from $B^{\star 27: 05-t r a n s g e n i c ~ r a t s ~(T r a n ~ e t ~ a l ., ~ 2006) ~ s h o w s ~ t h a t ~ h u m a n ~} \beta_{2}$-microglobulin $(\beta 2 \mathrm{~m})$ plays an important role in promoting the development of AS-like symptoms in these animals, supporting an hypothesis which we developed to account for the differential disease association of the $B^{* 27: 05}$ and the $B^{*} 27: 09$ subtypes ( [Uchanska-Ziegler and Ziegler, 2003a], [Uchanska-Ziegler and Ziegler, 2003b] and [Uchanska-Ziegler and Ziegler, 2008]). We also discovered a novel, dual peptide binding mode to $\mathrm{MHC}$ antigens that is only observed in the AS-associated subtype $\mathrm{B}^{\star} 27: 05$ (Hülsmeyer et al., 2004). This finding opened the possibility to correlate HLA-B27-restricted T cell reactivity with an exceptional structural property of a histocompatibility antigen. We also determined the first structure (Hülsmeyer et al., 2005a) of an MHC molecule in complex with a recombinant mAb exhibiting peptide-specific reactivity (Chames et al., 2000). Furthermore, we found that the intrinsic flexibility of the $B^{\star} 27: 05$ heavy chain $(\mathrm{HC})$ is independent of both the sequence as well as the conformation of a bound peptide, but is more pronounced than that exhibited by the $\mathrm{HC}$ of the $\mathrm{B}^{\star} 27: 09$ subtype ( [Fabian et al., 2008], [Fabian et al., 2010] and [Fabian et al., 2011]). These are the first results that reveal a correlation between dynamic properties of MHC molecules and a disease. Finally, we were able to shed new light on the process of T cell selection within the thymus ( [Rehm et al., 2000] and [Ziegler et al., 2009a]).

In the following sections, we will initially point out how our knowledge about HLA-B27 molecules and the way they present peptides has progressed over the last decade. In doing so, we will restrict ourselves mainly to X-ray crystallographic studies. However, we will then briefly refer to the progress obtained from spectroscopic, thermodynamic, and molecular dynamics (MD) simulation studies. Finally, we will apply the knowledge gained from structural and other studies of HLA-B27 subtypes to elaborate an hypothesis that seeks to explain the participation of selected HLA class I molecules in autoimmune processes.

\section{Production of peptide-complexed HLA class I molecules}

In producing complexes of HLA class I molecules and peptides, we have adapted the protocol described by Garboczi et al. (1992) not only to the extracellular HC fragment of HLA-B27 subtypes (Hülsmeyer et al., 2002) and other HLA class I molecules (Table 1) ( [Menssen et al., 1999], [Hillig et al., 2001], [Hülsmeyer et al., 2005a], [Kumar et al., 2009a] and [Kumar et al., 2009b]), but also to MHC class I molecules of the chicken ( [Hee et al., 2009] and [Hee et al., 2010] and unpublished results). For IR spectroscopy, the light chain of MHC class I complexes, $\beta_{2} \mathrm{~m}$, was labelled in vivo with ${ }^{13} \mathrm{C}$ and then complexed with unlabelled HLA-B27 HC and selected peptides in vitro ( [Fabian et al., 2008], [Fabian et al., 2010] and [Fabian et al., 2011]). Conversely, for fluorescence spectroscopic 
experiments, unlabelled $\mathrm{HLA}-\mathrm{B} 27 \mathrm{HC}$ and $\beta_{2} \mathrm{~m}$ were reconstituted with peptides carrying a fluorescent marker ( [Pöhlmann et al., 2004], [Uchanska-Ziegler et al., 2006], [Winkler et al., 2007] and [Narzi et al., 2008]).

\section{$X$-ray crystallographic studies}

Our X-ray crystallographic experiments with the HLA-B27 subtypes $B^{\star} 27: 05$ and $B^{\star} 27: 09$ have recently been extensively reviewed (Ziegler et al., 2009b). Therefore, we will mention here only one particularly striking aspect of these analyses in more detail, namely the influence that a seemingly minor difference within the binding groove can exert on the conformation of particular bound peptides. Residue 116 is the most polymorphic residue among HLA-B27 subtypes (http://hla.alleles.org) and also of HLA-B molecules in general (Reche and Reinherz, 2003). $B^{\star} 27: 05$ and $B^{\star} 27: 09$ must thus be regarded not only as valuable tools to study the involvement of HLA-B27 molecules in AS, but as models to understand the impact which small changes within the peptide binding groove can have on biophysical, biochemical, and functional properties of $\mathrm{MHC}$ molecules as a whole.

Fig. 1 and Fig. 2 provide an overview of some of the structures determined by us. The first three peptides are bound by both HLA-B27 subtypes in the canonical binding mode that is typical for MHC class I molecules: the peptides are anchored at both termini (more precisely, peptide position 2 (p2) and p9), and their middle bulges out of the binding groove. The polymorphic residue 116 is directly engaged by pLys 9 of the $\mathrm{m} 9$ peptide through a salt bridge (Fig. 1B). His 116 cannot establish a comparable contact with the side chain of pLys9, and this basic peptide residue is contacted by Asp77 instead, albeit with unfavourable geometry (Fig. 1C) (Hülsmeyer et al., 2002). This results in a pronounced destabilisation of the peptide $C$-terminus in the $B^{\star} 27: 09$ subtype, as shown by circular dichroism (CD) spectroscopy and differential scanning calorimetry (DSC) (Hillig et al., 2004) as well as by time-resolved fluorescence depolarisation spectroscopic measurements ( [Pöhlmann et al., 2004] and [Uchanska-Ziegler et al., 2006]), kinetic studies (Winkler et al., 2007), and molecular dynamics simulations ( [Pöhlmann et al., 2004] and [Ziegler et al., 2009a]). However, the m9 peptide remains firmly bound to the $B^{\star} 27: 05$ subtype. The difference in half life of the respective complexes is more than 200-fold, namely $\sim 1 \mathrm{~h}\left(\mathrm{~m} 9-\mathrm{B}^{\star} 27: 09\right)$ as opposed to about 10 days (m9-B*27:05) (Winkler et al., 2007). This demonstrates how a deeply buried $\mathrm{HC}$ residue can affect the dynamic properties of peptide-HLA-B27 complexes and explains why lysine is never found at the C-terminus in peptides eluted from $B^{\star 2}$ 27:09 molecules in vivo (López de Castro et al., 2004).

In contrast, the self-peptides TIS (RRLPIFSRL) (Fig. 1D and E) and pCatA (IRAAPPPLF) (Fig. 1F and G) possess hydrophobic $C$-termini that are needed by $B^{\star} 27: 09$ but are also accepted by $B^{\star} 27: 05$. In accord with nearly identical structures (Fig. 1D and E), thermodynamic measurements using CD spectroscopy and DSC have shown that complexes of both subtypes bound to the TIS peptide exhibit similar stability (Hülsmeyer et al., 2005b). Probably due to the presence of three proline residues, the structure of the $\mathrm{pCatA}$ peptide is comparatively rigid and assumes a virtually identical conformation not only in $B^{\star} 27: 05$ and $B^{*} 27: 09$ (Fig. $1 F$ and $G$ ), but even within the unrelated binding groove of the $B^{\star} 14: 02$ subtype (not shown, see Kumar et al., 2009a).

Prompted by functional studies carried out by our cooperating partners at the Università "La Sapienza" in Rome (summarised by Fiorillo and Sorrentino, 2009), we investigated also a group of sequencerelated peptides that are characterised, in particular, by the presence of a central arginine at $\mathrm{p} 5$ and a tryptophan (at p4) as well as a further arginine at p6. Healthy and diseased HLA-B27-positive individuals are able to mount immune responses against the viral peptide pLMP2 (RRRWRRLTV), revealing that the cross-reactivity of cytotoxic $T$ cells $(C T L)$ between the $B^{\star} 27: 05$ and the $B^{\star} 27: 09$ subtypes is often observed, although the peptide is bound to them in diametrically distinct conformations (Fiorillo et al., 2005). The B*27:05 subtype exploits the presence of Asp116 to contact the middle of this peptide by establishing a salt bridge between pArg5 and Asp116 (Fig. 2A), resulting in a distinct conformational change which we had first observed in the case of the complex of $B^{\star} 35: 01$ and the nef peptide, where Arg97 contacts pAsp5 via a salt bridge (not shown, see Menssen et al., 1999). In the case of the pLMP2 peptide, the $B^{\star} 27: 09$ subtype does not support this conformation, because a salt bridge cannot be formed between His116 and pArg5. Consequently, pLMP2 is bound canonically to $\mathrm{B}^{\star 2} 27: 09$ (Fig. 2B). 
The Italian group had also observed that $H L A-B 27$-restricted CTL against the sequence-related selfpeptide pVIPR (RRKWRRWHL) could readily be produced in $B^{\star 2} 27: 05$-positive individuals, but not in individuals who were typed as $B^{\star 2} 27: 09$ (Fiorillo et al., 2000). A plausible explanation is offered by the structural data: pVIPR is bound to $B^{\star} 27: 05$ in a completely unique, dual conformation which exhibits roughly equal occupancy (Fig. 2C) (Hülsmeyer et al., 2004). One of these binding modes is noncanonical, thus resembling the conformation of pLMP2 in complex with this subtype, while the other is canonical. In contrast, $B^{*} 27: 09$ reveals only the conventional binding mode (Fig. 2D). Therefore, the structural data suggest that it is the dual peptide binding mode in the $B^{\star} 27: 05$ subtype which leads to inappropriate selection of T cells within the thymus. We regard it as most likely that pVIPR is not statically bound to this subtype (there is some indirect support for this assumption, see Narzi et al. (2008) and Fabian et al. (2008)) and that CTL are "irritated" by the most likely extremely unusual dynamics exhibited by this peptide. This may result in "erroneous" survival of pVIPR-B*27:05-directed CTL. The pVIPR-B*27:09 structure, on the other hand, provides no basis for such perturbations and is expected to handle T cells in the "normal" way. For the first time, these combined functional and structural studies opened the possibility to correlate diseases that are differentially associated to the two HLA-B27 subtypes with a distinct molecular characteristic.

Since spondyloarthropathies like AS are inflammatory disorders, we investigated also the possibility that the citrullination of arginine residues within a peptide might affect its binding mode. Under the in vivo conditions prevailing in an inflammatory environment, citrulline is produced by deimination of arginine, converting the strongly basic, positively charged guanidinium group of its side chain into an uncharged amide ( [György et al., 2006] and [Makrygiannakis et al., 2006]). We chose a modified version of pVIPR for these studies: pVIPR-U5 ( $U$ = citrulline) could reasonably be expected to have lost contact with Asp116 due to the replacement of pArg5 by citrulline. This was indeed what we found (Fig. 2E), but we did not expect that the modified peptide would alter its binding mode completely in the case of $B^{\star} 27: 09$, where we observed an entirely unprecedented contact between His 116 and pU5 (Fig. 2F) (Beltrami et al., 2008). This non-canonical conformation bears a close resemblance to the corresponding binding mode of one of the conformations of the unmodified pVIPR peptide in $B^{\star} 27: 05$ (Fig. 2C), whereas the structure of the citrullinated peptide in $B^{\star} 27: 05$ is related to that of the nonmodified pVIPR in $B^{*} 27: 09$. Therefore, the situation is very complex, and all that one can say with confidence is that a prediction of the binding mode of an HLA-B27-bound peptide is a difficult and highly demanding task.

However, this task may be made easier by considerations that include functional characteristics. An example is provided by the self-peptide pCAC (SRRWRRWNR). We had previously described that $B^{\star 27}$ :05-restricted CTL with specificity for the self-peptide pGR (RRRWHRWRL) occasionally exhibit extensive cross-reactivity with other peptides such as pVIPR (Rückert et al., 2006), although these CTL were invariably found to lack cross-reactivity with $p C A C-B^{\star} 27: 05$ molecules. We reasoned that an explanation might be found in the structure of the complex, since contacts involving the C-terminal pArg9 of pCAC could well preclude the interaction of pArg5 with Asp116. This is indeed what we recently found: pArg9 is very firmly bound within the molecule's F pocket (Fig. 2G). Not only Asp116, but also Asp74 and Asp77 on the a1-helix of the $\mathrm{HC}$ are contacted via salt bridges, and there are multiple hydrogen bonds to the guanidinium moiety as well as several hydrophobic contacts with $\mathrm{HC}$ residues that flank the F pocket (Loll et al., 2011). The most notable feature resulting from this extensive network of atomic contacts between pArg9 and F pocket residues is the exclusion of pArg5 from interactions with Asp116. This leads to a re-orientation of the peptide within the groove: other than, e.g. in the case of pLMP2-B*27:05, it assumes a canonical conformation which very likely contributes to the lack of CTL cross-reactivity between HLA-B27 molecules presenting pGR, pVIPR, or pLMP2 on one hand and pCAC on the other. It is obvious that Asp116 is again that pivotal residue which is instrumental, by engaging with particular peptide residues or by avoiding distinct contacts, in leading the peptide to attain a specific conformation. The peptide binding characteristics of HLA-B27 subtypes are, however, usually not only dependent on a single, particular $\mathrm{HC}$ residue but are, as Galocha and López de Castro (2010) have shown, the result of interactions between sets of binding groove residues and amino acids of a peptide.

In conclusion, although we have learnt a lot in comparison to the results obtained by Madden, Wiley and colleagues during their pioneering structural studies of the $B^{\star} 27: 05$ molecule (see e.g. [Madden et al., 1992] and [Madden, 1995]), we still do not understand why a particular subtype, i.e. $B^{\star 27: 05}$, is AS-associated while another, e.g. $B^{\star 27: 09}$, is not. There are a bewildering number of hypotheses (reviewed by [Ziegler et al., 2009b] and [Taurog, 2010]), but none appears to account for all HLA$B 27 / A S-r e l a t e d$ aspects that require explanations. It is obvious, however, that the $B^{\star} 27: 05$ molecule 
possesses a number of features that endow it with very special peptide binding properties that are generally not observed in the case of the $B^{\star} 27: 09$ subtype. These considerations notwithstanding, what we currently lack is a convincing hypothesis how these distinct features can result, in a small number of $H L A-B 27-$ positive individuals, in spondyloarthropathies.

\section{Further biophysical studies}

As we have shown in the previous section, $\mathrm{X}$-ray crystallography can provide extremely detailed information on HLA-B27 complexes, but the structures obtained with this technique are largely static. It would, however, be highly desirable to acquire also information on the dynamic properties of these molecules. There are several techniques that are principally suitable, including fluorescence spectroscopy, MD simulation studies, and in particular nuclear magnetic resonance (NMR) spectroscopy. We have already employed the two former approaches ( [Pöhlmann et al., 2004], [Hülsmeyer et al., 2005b], [Uchanska-Ziegler et al., 2006], [Winkler et al., 2007] and [Narzi et al., 2008]) and have recently embarked on the latter (Schmieder et al., manuscript in preparation).

In the context of this review, we will, however, refer briefly to a further technique, isotope-edited IR spectroscopy. It employs the specific absorption of IR light to examine conformational differences between amino acid side chains and between distinct proteins and should thus be a suitable tool to analyse HLA-B27 subtypes, in particular since the amounts of protein required are relatively small. The results provide information on a number of stretching or bending vibrations within proteins that are characteristic of certain groups of atoms. In addition, hydrogen/deuterium $(H / D)$ exchange experiments can be carried out that provide additional information on the accessibility of a protein to solvent molecules. We have so far analysed the subtypes $B^{\star} 27: 05$ and $B^{\star} 27: 09$ in complex with four peptides (pVIPR, Fabian et al., 2008; TIS and pLMP2, Fabian et al., 2010; pVIPR-U5, Fabian et al., 2011). Independent of the peptide, the IR spectroscopic data indicate that the $\beta_{2} \mathrm{~m}$ molecules of all eight complexes exhibit virtually indistinguishable conformational and dynamic properties. However, the $\mathrm{B}^{\star 2} 27: 05 \mathrm{HC}$ was found to display a higher degree of conformational flexibility at physiological

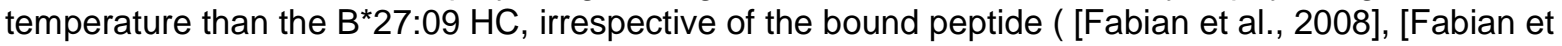
al., 2010] and [Fabian et al., 2011]). An example for the type of data obtained with the peptides pVIPR and TIS is provided in Fig. 3.

The interpretation of these results is, however, not straightforward, even when detailed structural information is at hand as in the case of the four peptides investigated here ( [Hülsmeyer et al., 2004], [Hülsmeyer et al., 2005b], [Fiorillo et al., 2005] and [Beltrami et al., 2008]). For example, although we can determine if $\alpha$-helical residues exhibit dynamic differences between the two HLA-B27 subtypes, the IR spectroscopic approach applied by us does not provide hints regarding which part of the molecule could be affected. It is only evident that the a3-domain of the molecules, which does not contain $\alpha$-helices, cannot be responsible for the differences. The same reservation applies to the H/D exchange experiments. By taking the results of MD simulations (Fabian et al., 2008) into account and the fact that the two molecular complexes differ only by a single amino acid residue, we have suggested a scenario which we regard as plausible. It involves the water networks around the polymorphic residue 116 which are tighter in the $B^{\star} 27: 09$ subtype than in $B^{\star} 27: 05$. We envisage that these water clusters influence an up- and down movement of the peptide whose main chain is suspended in a highly conserved fashion between the two a-helices of the binding groove, involving residues Asp77 and Trp147. In turn, this movement will lead to an inward or outward movement of the a-helices which could not only influence the IR spectrum of a given subtype, but also the interaction of the latter with effector cells (Fabian et al., 2010). Advanced mass spectrometry techniques might eventually tell us which part of the HLA-B27 HC is affected by the subtype-specific changes. NMR spectroscopy appears as an alternative, although HLA class I molecules are already relatively large for this type of analysis. In any case, our results with the two HLA-B27 subtypes demonstrate that the combination of advanced biophysical techniques that complement each other is an extremely powerful way to obtain very detailed information on these molecules.

\section{HLA class I alleles and autoimmunity}

$H L A-B 27$ subtypes are not the only HLA class I alleles that are associated with diseases with a suspected autoimmune etiology, but here the association is by far the strongest and the best 
documented. Nevertheless, it was already noted 15 years ago, that the HLA-A3 and HLA-A11 (now HLA-A*03:01 and HLA-A*11:01) antigens which are part of the "HLA-A3 supertype", are strongly associated with immune aberrations among healthy Venezuelans (Makhatadze et al., 1995). Remarkably, the authors concluded that "an association between HLA class I molecules and disease may be very strong but never absolute... and may indicate the potentiality under certain circumstances for contributing to... the development of pathologic processes...". This could be said also for HLA-B27 and spondyloarthropathies, where only $\sim 5 \%$ of the HLA-B27-positive individuals do in fact acquire AS.

The evidence that the alleles $A^{*} 03: 01$ and $A^{*} 11: 01$ are associated not only with immunological abnormalities but real autoimmune diseases is relatively persuasive: $A^{*} 03: 01$ has been found to increase the risk for MS two-fold, independent of HLA class II alleles, with which MS is also associated ( [Fogdell-Hahn et al., 2000], [Harbo et al., 2004] and [Burfoot et al., 2008]). In addition, clear-cut evidence for an involvement of the $A^{*} 03: 01$ antigen itself in MS has been obtained in a mouse model (Friese et al., 2008). These authors studied "humanised" mice expressing the $A^{*} 03: 01$ allele together with an autoreactive, $A^{*} 03: 01$-restricted T cell receptor (TCR) with specificity for the myelin proteolipid protein-derived PLP45-53 peptide (KLIETYFSK). It was established that $A^{*} 03: 01$ has a role in the induction of a disease resembling human MS, apparently because of inappropriate thymic selection. However, the additional expression of the HLA-A2 antigen in heterozygous $A^{*} 02: 01 / A^{*} 03: 01$ transgenic mice bearing the same TCR transgene protected from MS. This result suggests, as Friese et al. (2008) point out, that $A^{*} 03: 01$-autoreactive $T$ cells can be deleted during selection on $A^{*} 02: 01$ molecules within the thymus. However, as it was known that $A^{*} 02: 01$ molecules can only bind peptides with a C-terminal hydrophobic anchor residue (Reche et al., 2005), it remained enigmatic to the authors how this seemingly paradoxical result can be explained. In obvious agreement with their findings, it has been shown that the $A^{*} 02: 01$ allele exerts a protective effect in humans when it is coexpressed with the MS-associated HLA class II allele DRB1*1501 (Fogdell-Hahn et al., 2000).

Other HLA class I alleles belonging to the HLA-A3 supertype are also associated with autoimmune diseases, although the evidence for a direct involvement of the antigen itself is not as compelling as for $A^{*} 03: 01$. A subgroup of rheumatoid arthritis patients bears the $A^{*} 11: 01$ allele ( [Bhatia et al., 1988] and [Tsuchiya et al., 2001]), and the same has been found in the case of children with steroidresponsive nephrotic syndrome in Southeast Asia (Cheung et al., 2002). In addition, associations of

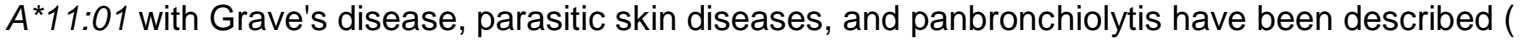
[Farid et al., 1980], [Morsy et al., 1990] and [Park et al., 1999]). Similarly, $A^{*} 31: 01$ has been reported to be associated with Vogt-Koyanagi-Harada syndrome in Korean ophthalmologic patients (Kim et al., 2000), elevated levels of the HLA-A33 antigen have been found in the blood of Japanese individuals affected by biliary atresia (Nakada et al., 1997), and the frequency of $A^{*} 68: 01$ is increased in patients with dermatomyositis (O'Hanlon et al., 2005). The products of all these HLA-A alleles are serologically closely related, and this is also evident from the amino acid sequences of their $\alpha 1$ - and a2-domains which are more similar to each other than to that of the $A^{*} 02: 01 \mathrm{HC}$ (Fig. 4).

Despite a pronounced dissimilarity with regard to many of their binding groove residues (Fig. 4), however, the $B^{\star}$ 27:05 molecule and antigens of the HLA-A3 supertype share a preference for peptides carrying a basic C-terminus, most often lysine (Reche et al., 2005). This may be an absolute requirement as in the case of the HLA-A molecules, or just an inclination ( $\left.B^{*} 27: 05\right)$. It appears that the conserved $\mathrm{F}$ pocket $\mathrm{HC}$ residues Asp74, Asp77, and Asp116 could be instrumental in mediating this binding, and the few structures that are available to date with peptides bearing a basic $\mathrm{C}$-terminus (m9-B*27:05, pCAC-B*27:05, gag-B*27:05, flu-B*27:05, SNP-A*11:01, pDP-A*68:01, Fig. 5) ( [Hülsmeyer et al., 2002], [Loll et al., 2011], [Li and Bouvier, 2004], [Li et al., 2005], [Blicher et al., 2005] and [Silver et al., 1992]) demonstrate indeed that this is the case. In particular, the multiple contacts made by pArg9 of the pCAC or the flu peptides exploit all these $\mathrm{HC}$ residues by engaging in salt bridges (Fig. 5C), and the tip of the pLys9 side chain of the other peptides forms a salt bridge to Asp116 (Fig. 5A, D and E), with only the longer gag peptide being an exception (Stewart-Jones et al., 2005). In the $B^{*} 27: 09$ subtype, however, the salt bridge-mediated contact between the $\mathrm{m} 9$ peptide and Asp77 is geometrically unfavourable and does not lead to a firm anchoring of $m 9$ within this subtype's binding groove (Fig. 5B) ( [Hülsmeyer et al., 2002], [Pöhlmann et al., 2004], [Winkler et al., 2007], [Narzi et al., 2008] and [Ziegler et al., 2009a]). Peptide binding characteristics can be assessed particularly well when the interactive 3D mode is activated by clicking on the figure. The procedure to embed multimedia content (apart from molecular models and structures of zoological specimens, also videos, and audios) into electronic publications has been pioneered by us ( [Kumar et al., 2008], [Kumar et al., 2009a], [Kumar et al., 2009b], [Kumar et al., 2010], [Ziegler et al., 2008], [Ziegler et al., 2009a], [Ziegler et al., 2010b], [Ziegler et al., 2010c], [Ziegler et al., 2011], [Hee et al., 2010] and [Loll 
et al., 2011]). This development has been welcomed by structural biologists ( [Tyzack, 2008], [Hodis and Sussman, 2009] and [Anon., 2009]).

In conclusion, $B^{\star} 27: 05$ and the autoimmunity-associated antigens of the HLA-A3 supertype have the ability to bind peptides possessing a $\mathrm{C}$-terminal basic residue with high affinity. This property distinguishes them sharply from the more conventional antigens $B^{*} 27: 09$ and $A^{*} 02: 01$ which require peptides with a hydrophobic C-terminus for high affinity interaction.

\section{F pocket architecture and thymic $T$ cell selection}

Having demonstrated that the architecture of the $\mathrm{F}$ pocket is responsible for the differential preference of HLA class I molecules for peptides with distinct C-termini, we can consider the functional consequences of these differences. The results of Fiorillo et al. (2000) as well as Friese et al. (2008) demonstrate that there may be a problem with the $T$ cell repertoires which appear to be selected within the thymus in an unconventional fashion, resulting in a high proportion of $B^{* 27: 05-}$ or $A^{*} 03: 01$ restricted T cells with autoreactivity against the pVIPR or PLP peptides, respectively. Thymic $T$ cell selection is essential to make sure that T cells mature to exhibit two properties: (i) they should be MHC-restricted, i.e. exhibit a preference for an MHC class I or II molecule expressed by the host, and (ii) they must lack strong reactivity with self-antigens to avoid autoimmunity. T cell selection takes place in two thymic compartments, the cortex, where "positive" selection, and the medulla, in which "negative" selection takes place. Specialised cells mediate these selection processes, namely cortical (cTEC) and medullary (mTEC) thymic epithelial cells.

T cells appear initially to be "educated" on cTEC to recognise only the product of a particular MHC allele (positive selection). Those T cells that survive this step will carry a TCR with intermediate or low affinity towards an $\mathrm{MHC}$ molecule, while those with too high or too low affinity are eliminated. After migrating towards the medulla, the MHC-restricted, but necessarily still autoreactive $\mathrm{T}$ cells are challenged by an enormous array of peptides that are presented on mTEC-expressed MHC molecules due to the promiscuous transcription of many tissue-specific genes within these cells (reviewed by Klein et al. (2009)). T cells that carry TCR with an affinity for peptide-MHC complexes above a certain threshold will be eliminated (negative selection) and only those that do not recognise these complexes will survive. The normal outcome of these consecutive selection steps are T cells with the desired properties: they are potentially reactive with a foreign peptide that is presented by that $\mathrm{MHC}$ molecule on which these cells had originally "learnt" to be MHC-restricted and they lack reactivity with MHC molecules that present self-peptides.

Thymic $T$ cell selection has been dealt with in hundreds of articles and it is possible here to mention only a few reviews ( [von Boehmer, 1994], [Nossal, 1994], [von Boehmer et al., 2003], [Starr et al., 2003], [Huseby et al., 2008], [Klein et al., 2009] and [Takahama et al., 2010]). Importantly, although differing in detail, virtually all authors arrive at the conclusion that positive as well as negative $T$ cell selection relies on $\mathrm{MHC}$ molecules that present a peptide.

\section{An alternative view of $T$ cell selection}

We have recently also reviewed this topic, with a particular emphasis on positive T cell selection. Prompted by our work with monoclonal antibodies possessing peptide-dependent reactivity towards MHC class I molecules (Rehm et al., 2000), experiments on the biophysical properties of the B*27:05 and $B^{\star}$ 27:09 molecules, and a recent article describing a novel proteasome subunit that is expressed in mouse cTEC (Murata et al., 2007), we have come to the conclusion that the positive selection of T cells does not work as conventionally envisaged. Instead, we postulate that partially peptide-filled or "empty", i.e. peptide-devoid, MHC molecules must be central to this selection process (Ziegler et al., 2009a).

This assumption relies on the fact that the cTEC-specific $\beta 5 t$ subunit of the proteasome, a cytosolic proteolytic machine, is responsible for a substantial enrichment of peptides with basic $\mathrm{C}$-termini. Therefore, the peptides with which MHC class I molecules are supplied in CTEC differ from those present in $\mathrm{mTEC}$. In CTEC, the peptides will not be optimally accommodated in the binding grooves of 
many $\mathrm{MHC}$ class I molecules, because hydrophobic C-termini are essential for high-affinity interactions between a peptide and the vast majority of peptide binding grooves (examples include $B^{*} 27: 09$ and $\left.A^{*} 02: 01\right)$. Conversely, in $m T E C$, the "normal" proteasome is at work, producing peptides with hydrophobic as well as basic C-termini. The peptide repertoire in ITEC can thus serve both the majority of MHC class I molecules as well as the minority that requires a basic peptide $\mathrm{C}$-terminus for high-affinity interaction like $A^{*} 03: 01$. These results lead to the inescapable conclusion that there is a principal difference between cTEC and MTEC that allows T cells to be selected on structurally distinct MHC class I molecules (we will not be concerned here with class II molecules, where the situation might be equivalent, although differences do exist).

\section{$T$ cell selection within the thymic cortex}

There is agreement among immunologists with regard to negative selection: all MHC molecules on mTEC carry peptides which fit optimally into the binding grooves that are available. It has, however, not yet been accepted that peptide-devoid MHC molecules might play a crucial role in positive selection, as suggested by us, although the situation is slowly changing ( [Hogquist and Xing, 2010] and [Crites and Varma, 2010]). The scenario which we envisage for positive selection ( [Rehm et al., 2000] and [Ziegler et al., 2009a]) involves the following steps: (i) the thymoproteasome produces predominantly peptides with a basic C-terminal residue, (ii) these peptides are transported into the endoplasmic reticulum, where they are loaded into the binding grooves of $\mathrm{MHC}$ class I molecules. Depending on the anchor preference, there are two possibilities: (iii-a) a given peptide will be weakly bound due to unfavourable interactions between its $\mathrm{C}$-terminus and $\mathrm{F}$ pocket residues (expected for the majority of subtypes), or (iii-b) the peptide will be firmly bound (expected for $B^{\star} 27: 05, A^{*} 03: 01$ and related subtypes).

The consequences of case (iii-a) will be that the molecule may fail to reach the cell surface due to an insufficient half-life. Alternatively, it may reach the cell surface but the peptide will only transiently be bound as in the case of $B^{\star} 27: 09$ in complex with the m9 peptide ( [Pöhlmann et al., 2004], [Winkler et al., 2007], [Narzi et al., 2008] and [Ziegler et al., 2009a]). Based on our comparative kinetic studies of the $m 9-B^{\star} 27: 05$ and $m 9-B^{*} 27: 09$ complexes, we predict that peptides will disappear relatively rapidly from the binding grooves of $B^{\star} 27: 09$ complexes, leaving empty MHC class I molecules behind. The half-lives of these transiently occupied or peptide-devoid molecules are unknown, but since cell surface-expressed empty MHC class I molecules have been found in vivo ( [Benjamin et al., 1991] and [Fahnestock et al., 1992]), there is no reason to exclude them from our considerations. In addition, even half-lives of minutes might permit the scanning of thousands of $T$ cells on the surface of CTEC, because the individual recognition process between a TCR and an MHC molecule is much shorter than the complexes' half-lives. T cells can thus obtain the chance to be selected on partially filled or completely peptide-devoid MHC molecules. We have already pointed out ( [Rehm et al., 2000] and [Ziegler et al., 2009a]) that the latter would be ideal to fulfil a task during positive selection on cTEC, where the major objective is to select those T cells whose TCR recognise a given MHC molecule (mainly its $\alpha$-helices, see the review by Rudolph et al., 2006) with intermediate or low affinity. As pointed out by Schumacher and Ploegh (1994), this recognition process would probably be obstructed by the majority of bound peptides.

Case (iii-b), with firmly bound peptides due to the presence of a C-terminal basic residue during positive selection, can be predicted to have two outcomes: (iii-b1) involves T cells that recognise the complex of peptide, $\mathrm{HC}$, and $\beta_{2} \mathrm{~m}$ (peptide-MHC) on cTEC with high affinity, thus resembling the situation in negative selection on mTEC. Consequently, these self-reactive T cells would be deleted. (iii-b2) considers T cells that recognise peptide-MHC with intermediate or low affinity. The outcome of this selection step would resemble the scenario of (iii-a), with a single important difference: while the selection onss cTEC will normally (e.g. $\mathrm{B}^{\star} 27: 09$ molecules) take place by means of peptide-devoid molecules, peptide-MHC complexes are the molecules on which the selection takes place in the case of $B^{\star} 27: 05, A^{*} 03: 01$, and comparable antigens. The selected T cells might thus be more "peptideoriented" than those in the situation iii-a, where peptides, as envisaged by us, do not play a role. This peptide-directed interaction could promote $T$ cell cross-reactivity, but there is presently no experimental support for this belief.

It must currently remain an open question whether the lack of appropriate selection in the case of $B^{\star 2}$ 27:05-restricted, pVIPR-directed T cells ( [Fiorillo et al., 2000] and [Hülsmeyer et al., 2004]) is due to 
cortical or medullary selection. However, the ability of $B^{\star} 27: 05$ molecules to bind certain peptides with high affinity already during positive selection could be taken as an indication that things start to get out of control already in the thymic cortex. In the case of $A^{*} 03: 01$-transgenic mice and MS (Friese et al., 2008), we regard the evidence as even more persuasive: $A^{*} 03: 01$ molecules will invariably be filled on CTEC by peptides engaging in high-affinity interactions. A proper deletion of autoreactive T cells, according to the scenario which we favour, can thus not take place. Consequently, $A^{*} 03: 01$-transgenic mice will have an elevated chance to acquire MS, initiated by the activity of the autoreactive TCRtransgene. In the heterozygous $A^{*} 02: 01 / A^{*} 03: 01$-transgenic animals, however, it will be the empty $\mathrm{A}^{*} 02: 01$ molecule on cTEC whose $\mathrm{HC}$ is sufficiently similar (Fig. 4) to that of the $\mathrm{A}^{*} 03: 01 \mathrm{HC}$ to permit recognition during positive selection also of the receptor specified by the human TCR-transgene. This setting takes full account of the fact that the PLP peptide will not bind to $A^{*} 02: 01$ molecules with high affinity, indicating that it cannot be the negative selection step within the medulla which is responsible for the healthy state of the heterozygous $A^{*} 02: 01 / A^{*} 03: 01$-transgenic mice.

\section{T cell selection within the thymic medulla}

According to our hypothesis, the T cells entering the medulla may thus have been confronted with structurally distinct molecules, depending on the MHC alleles available. One set of T cells ("N" for normal selection) will have been selected on empty molecules, another set ("A" for autoimmunityrelated) on MHC molecules with a peptide-filled groove. Set "N" will be depleted substantially by negative selection with peptide-filled molecules on mTEC, while set " $A$ " will probably only moderately be diminished further on peptide-MHC complexes that largely resemble those encountered already during cortical selection. We therefore predict that set " $\mathrm{A}$ ", which has never had the chance to undergo a proper positive selection, will contain a much higher number of $T$ cells with intermediate or low affinity towards self-antigens than the " $N$ " $T$ cell set. It is therefore conceivable that the " $A$ " $T$ cells might cause autoimmune disease when other factors, e.g. infectious agents or a specific genetic predisposition as in AS (Australo-Anglo-American Spondyloarthritis Consortium, 2010), come together. This could also explain why by far not all individuals with $B^{\star} 27: 05$ or $A^{*} 03: 01$ succumb to one of the subtype-associated disorders.

In addition, two further factors related to negative selection will conceivably contribute to autoimmunity. Using in silico thymic selection experiments, Košmrlj et al. (2010) have argued that the T cell repertoires of individuals with certain HLA class I alleles, among them $B^{\star 2} 27: 05$, will be less comprehensively depleted by medullary thymic selection than in the case of individuals with most other alleles. This appears due to the fact that peptides which are able to bind to the former alleles will be less abundant (strict requirement for certain less frequent anchor amino acids such as, for example, pArg2 in the case of HLA-B27 molecules) than peptides that are able to exhibit a more promiscuous binding. Furthermore, the expression of tissue-specific genes is usually elevated within the tissue that is targeted in autoimmunity (e.g. the brain in the case of MS), thereby facilitating the stimulation of autoreactive T cells that have survived negative T cell selection on mTEC due to insufficient affinity of their TCR for any of the many different pMHC that are available.

\section{A role for MHC heavy chain flexibility as well?}

One particularly interesting and very novel aspect of peptide-MHC complexes that may also play a role in autoimmune phenomena refers to the intrinsic $\mathrm{HC}$ flexibility that is greater in $\mathrm{B}^{\star} 27: 05$ than in $\mathrm{B}^{\star} 27: 09$, independent of the conformation or the sequence of a peptide ( [Fabian et al., 2008], [Fabian et al., 2010] and [Fabian et al., 2011]). We do not know whether this is also a property of other disease-related $\mathrm{HC}$, and how this property might, e.g., affect the binding of TCR. Therefore, the study of the other pair of subtypes that is differentially associated with $A S, B^{\star} 27: 04$ and $B^{\star} 27: 06$, might be fruitful not only by crystallographic studies (for initial experiments, see [Loll et al., 2004] and [Zawacka et al., 2005]), but also by IR spectroscopy. It must be mentioned in this context, that there are some indications from MD simulations that a $\mathrm{B}^{\star} 27: 05$ binding groove that has bound a peptide with a $\mathrm{C}$ terminal basic residue (m9-B*27:05) may in fact be less flexible than that of $B^{\star} 27: 09$ with the same peptide ( [Pöhlmann et al., 2004] and [Ziegler et al., 2009a]). We are not yet sure whether the intrinsic flexibility of the $B^{\star} 27: 05$ or $B^{\star} 27: 09 \mathrm{HC}$ is also influenced by basic $C$-termini, but this could be determined by extending the analyses with pVIPR, pLMP2, TIS, and pVIPR-U5 to the m9 peptide. If the $B^{\star} 27: 05 \mathrm{HC}$ would really be more rigid when a basic side chain occupies the $F$ pocket, this could 
well affect the interaction of effector molecules with this and comparable antigens, not only during selection processes within the thymus, but during physiological and pathological immune responses as well.

\section{Conclusions}

We are of course aware that some elements of our considerations are currently speculative. However, we regard it as conclusive that the $F$ pocket of $B^{*} 27: 05$ and antigens of the HLA-A3 supertype will be instrumental in creating a particular $T$ cell repertoire that increases the chances of acquiring an autoimmune disease. Insufficient peptide supply in the course of negative selection (Košmrlj et al., 2010) as well as the relative densities of particular peptide-MHC complexes in thymic compartments and in the target tissues of autoimmune processes are likely to contribute as well. Furthermore, an unusually rigid $\mathrm{MHC}$ class I molecule might well be a hindrance for the efficient recognition by effector cells. At this stage, we consider it as likely that a mosaic of molecular contributors and environmental factors like a bacterial or a viral infection, will in the end determine whether an autoimmune disease will develop or not.

We can, however, say that the study of the $B^{\star} 27: 05$ and $B^{\star} 27: 09$ subtypes by biophysical techniques has already greatly added to our understanding of how these two molecules, and minimally distinct histocompatibility antigens in general, can exert a differential influence on important functional properties of the body's immune system. We expect that the inclusion of additional techniques, such as NMR spectroscopy, will enhance our understanding even further, in particular with regard to the dynamic properties of these molecules, and it is obvious that these studies should also be extended to include receptors on effector cells. Finally, we hope that these studies will also provide a substantial contribution to unravel the complex causes of autoimmune diseases that are associated with HLA class I alleles.

\section{Acknowledgements}

The authors are grateful to the following colleagues, some of whom participated for more than a decade in the studies referred to in this article, most of them in Berlin, but some also abroad (in alphabetical order): U. Alexiev, S. Beck (Hinxton, Cambridge, now London, U.K.), A. Beltrami, M.G. Bicalho (Curitiba, Brazil), R.A. Böckmann (Göttingen, Zürich (Switzerland), and Homburg, now Erlangen), P.G. Coulie (Brussels, Belgium), O. Daumke, G. Dohr (Graz, Austria), M.T. Fiorillo (Rome, Italy), G. Füst (Budapest, Hungary), A. Grahn (Dresden), R. Hillig, M. Hülsmeyer (now Homburg), H. Huser, T. Kellermann, H. Kentenich, P. Kumar (now Cambridge, U.S.A.), K. Laun ${ }^{\dagger}$, J.A. López de Castro (Madrid, Spain), R. Menssen (now Stuttgart), M.M. Miller (Duarte, U.S.A.), R. Misselwitz, C.A. Müller (Tübingen), D. Naumann, C. Rückert, P.S.C. Santos, C. Seitz, A. Rehm, R. Sorrentino (Rome, Italy), J.L. Strominger (Cambridge, U.S.A.), A. Volz, L. Walter (Göttingen), H. Welfle, K. Welfle, A. Zawacka (now Warsaw, Poland), A. Ziegler (now Cambridge, U.S.A.), and J. Ziegler (Hamburg). We would also like to thank the following technicians without whose excellent work our studies could not have been carried out (in alphabetical order): C. Alings, C. Backhaus, A. Eismann, M. Rühl, C. Schnick, G. Wille, A. Zank, and M. Zirra. Finally, this work depended on continuous financial support and we thank the following organisations for their contributions: Berliner Krebsgesellschaft (Ernst von Leyden Stipendium to A. Beltrami, C.S. Hee, and P.S.C. Santos, grant to B. Uchanska-Ziegler and W. Saenger); Deutsche Forschungsgemeinschaft, Bonn (Sfb 449, Teilprojekt B6; UC8/2-1); European Union (EFRE 2000-2006 2ü/2); Fonds der Chemischen Industrie, Frankfurt (Kekulé-Stipendium to A. Zawacka, grant to B. Loll and W. Saenger); Land Berlin (NaFöG- and Elsa Neumann-Stipendium to C.S. Hee, T. Kellermann, P. Kumar, R. Menssen, P.S.C. Santos, A. Zawacka); Monika-KutznerStiftung, Berlin; Sonnenfeld-Stiftung, Berlin; VolkswagenStiftung, Hannover (I/72 740, I/75 196, I/79 983, I/79 989); Wellcome Foundation (Biomedical Research Collaboration grant).

\section{Appendix A. Supplementary data}

Supplementary data associated with this article can be found, in the online version, at doi:10.1016/j.ejcb.2011.03.003. 


\section{References}

Anaya, J.-M., 2010. The autoimmune tautology. Arthritis Res. Ther. 12, 147.

Anon., 2009. 3D presentation of structural and image data. J. Biol. Chem. 284, 21101.

Australo-Anglo-American Spondyloarthritis Consortium (TASC), Reveille, J.D., Sims,

A.M., Danoy, P., Evans, D.M., Leo, P., Pointon, J.J., Jin, R., Zhou, X., Bradbury, L.A., Appleton, L.H., Davis, J.C., Diekman, L., Doan, T., Dowling, A., Duan, R., Duncan, E.L., Farrar, C., Hadler, J., Harvey, D., Karaderi, T., Mogg, R., Pomeroy, E., Pryce, K., Taylor, J., Savage, L., Deloukas, P., Kumanduri, V., Peltonen, L., Ring, S.M., Whittaker, P., Glazov, E., Thomas, G.P., Maksymowych, W.P., Inman, R.D., Ward, M.M., Stone, M.A., Weisman, M.H., Wordsworth, B.P., Brown, M.A., 2010. Genome-wide association study of ankylosing spondylitis identifies non-MHC susceptibility loci. Nat. Genet. 42, 123127.

Beltrami, A., Rossmann, M., Fiorillo, M.T., Paladini, F., Sorrentino, R., Saenger, W., Kumar, P., Ziegler, A., Uchanska-Ziegler, B., 2008. Citrullination-dependent differential presentation of a selfpeptide by HLA-B27 subtypes. J. Biol. Chem. 283, 27189-27199.

Benjamin, R.J., Madrigal, J.A., Parham, P., 1991. Peptide binding to empty HLA-B27 molecules of viable human cells. Nature 351, 74-77.

Bhatia, K., Richens, J., Prasad, M.L., Koki, G., 1988. High prevalence of the haplotype HLA-A11. B27 in arthritis patients from the highlands of Papua New Guinea. Tissue Antigens 31, 103-106.

Blicher, T., Kastrup, J.S., Buus, S., Gajhede, M., 2005. High-resolution structure of HLA-A*1101 in complex with SARS nucleocapsid peptide. Acta Crystallogr. D 61, 1031-1040.

Brewerton, D.A., Hart, F.D., Nicholls, A., Caffrey, M., James, D.C., Sturrock, R.D., 1973. Ankylosing spondylitis and HLA-B27. Lancet 1, 904-907.

Burfoot, R.K., Jensen, C.J., Field, J., Stankovich, J., Varney, M.D., Johnson, L.J., Butzkueven, H., Booth, D., Bahlo, M., Tait, B.D., Taylor, B.V., Speed, T.P., Heard, R., Stewart, G.J., Foote, S.J., Kilpatrick, T.J., Rubio, J.P., 2008. SNP mapping and candidate gene sequencing in the class I region of the HLA complex: searching for multiple sclerosis susceptibility genes in Tasmanians. Tissue Antigens $71,42-50$.

Chames, P., Hufton, S.E., Coulie, P.G., Uchanska-Ziegler, B., Hoogenboom, H.R., 2000.

Direct selection of a human antibody fragment directed against the tumor T-cell epitope HLA-A1-

MAGE-A1 from a nonimmunized phage-Fab library. Proc. Natl. Acad. Sci. U.S.A. 97, 7969-7974.

Cheung, W., Ren, E.C., Chan, S.H., Gong, W.K., Yap, H.K., 2002. Increased HLA-A*11 in Chinese

children with steroid-responsive nephrotic syndrome. Pediatr. Nephrol. 17, 212-216.

Crites, T.J., Varma, R., 2010. On the issue of peptide recognition in T cell development.

Self/Nonself 1, 55-61.

D'Amato, M., Fiorillo, M.T., Carcassi, C., Mathieu, A., Zuccarelli, A., Bitti, P.P., Tosi, R., Sorrentino, R., 1995. Relevance of residue 116 of HLA-B27 in determining susceptibility to ankylosing spondylitis.

Eur. J. Immunol. 25, 3199-3201.

Dangoria, N.S., DeLay, M., Kingsbury, D.J., Mear, J.P., Uchanska-Ziegler, B., Ziegler, A., Colbert, R.A., 2002. HLA-B27 misfolding is associated with aberrant intermolecular disulfide bond formation (dimerization) in the endoplasmic reticulum. J. Biol. Chem. 277, 23459-23468.

Diaz-Pe na, R., Blanco-Gelaz, M.A., Njobvu, P., Lopez-Vazquez, A., Suarez-Alvarez, B., Lopez-

Larrea, C., 2008. Influence of HLA-B ${ }^{\star} 5703$ and HLA-B* 1403 on susceptibility to spondyloarthropathies in the Zambian population. J. Rheumatol. 35, 2236-2240.

Ehlers, A., Beck, S., Forbes, S., Trowsdale, J., Volz, A., Younger, R., Ziegler, A., 2000. MHC-linked olfactory receptor loci exhibit polymorphism and contribute to extended HLA/OR haplotypes. Genome Res. 10, 1968-1978.

Fabian, H., Huser, H., Narzi, D., Misselwitz, R., Loll, B., Ziegler, A., Bockmann, R.A., UchanskaZiegler, B., Naumann, D., 2008. HLA-B27 subtypes differentially associated with disease exhibit conformational differences in solution. J. Mol. Biol. 376, 798-810.

Fabian, H., Huser, H., Loll, B., Ziegler, A., Naumann, D., Uchanska-Ziegler, B., 2010. HLA-B27 heavy chains distinguished by a micropolymorphism exhibit differential flexibility. Arthritis Rheum. 62, 978987.

Fabian, H., Loll, B., Huser, H., Uchanska-Ziegler, B., Naumann, D., Ziegler, A. Influence of inflammation-related changes on conformational characteristics of HLA-B27 subtypes as detected by IR spectroscopy. FEBS J., in press 2011.

Fahnestock, M.L., Tamir, I., Narhi, L., Bjorkman, P.J., 1992. Thermal stability comparison of purified empty and peptide-filled forms of a class I MHC molecule. Science 258, 1658-1662.

Farid, N.R., Moens, H., Larsen, B., Payne, R., Saltman, K., Fifield, F., Ingram, D.W., 1980. HLA haplotypes in familial Graves' disease. Tissue Antigens 15, 492-500. 
Fernando, M.M.A., Stevens, C.R., Walsh, E.C., De Jager, P.L., Goyette, P., Plenge, R.M., Vyse, T.J., Rioux, J.D., 2008. Defining the role of the MHC in autoimmunity: a review and pooled analysis. PLoS Genet. 4, e1000024.

Fiorillo, M.T., Maragno, M., Butler, R., Dupuis, M.L., Sorrentino, R., 2000. CD8(+) T-cell autoreactivity to an HLA-B27-restricted self-epitope correlates with ankylosing

spondylitis. J. Clin. Invest. 106, 47-53.

Fiorillo, M.T., Ruckert, C., Hulsmeyer, M., Sorrentino, R., Saenger, W., Ziegler, A., Uchanska-Ziegler, B., 2005. Allele-dependent similarity between viral and selfpeptide presentation by HLA-B27 subtypes. J. Biol. Chem. 280, 2962-2971.

Fiorillo, M.T., Sorrentino, R., 2009. T-cell responses against viral and self-epitopes and HLA-B27 subtypes differentially associated with ankylosing spondylitis. Adv. Exp. Med. Biol. 649, 255-262.

Fogdell-Hahn, A., Ligers, A., Grønning, M., Hillert, J., Olerup, O., 2000. Multiple sclerosis: a modifying influence of HLA class I genes in an HLA class II associated autoimmune disease. Tissue Antigens $55,140-148$.

Friese, M.A., Jakobsen, K.B., Friis, L., Etzensperger, R., Craner, M.J., McMahon, R.M., Jensen, L.T., Huygelen, V., Jones, Y.E., Bell, J.I., Fugger, L., 2008. Opposing effects of HLA class I molecules in tuning autoreactive CD8+ T cells in multiple sclerosis. Nat. Med. 14, 1227-1235.

Galocha, B., Lopez de Castro, J.A., 2010. Mutational analysis reveals a complex interplay of peptide binding and multiple biological features of HLA-B27. J. Biol. Chem. 285, 39180-39190.

Garboczi, D.N., Hung, D.T., Wiley, D.C., 1992. HLA-A2-peptide complexes: refolding and crystallization of molecules expressed in Escherichia coli and complexed with single antigenic peptides. Proc. Natl. Acad. Sci. U.S.A. 89, 3429-3433.

Goddard, C.A., Butts, D.A., Shatz, C.J., 2007. Regulation of CNS synapses by neuronal MHC class I. Proc. Natl. Acad. Sci. U.S.A. 104, 6828-6833.

Gyorgy, B., Toth, E., Tarcsa, E., Falus, A., Buzas, E.I., 2006. Citrullination: a posttranslational modification in health and disease. Int. J. Biochem. Cell Biol. 38, 1662-1677.

Harbo, H.F., Lie, B.A., Sawcer, S., Celius, E.G., Dai, K.Z., Oturai, A., Hillert, J., Lorentzen, A.R., Laaksonen, M., Myhr, K.M., Ryder, L.P., Fredrikson, S., Nyland, H., Sørensen, P.S., Sandberg Wollheim, M., Andersen, O., Svejgaard, A., Edland, A., Mellgren, S.I., Compston, A., Vartdal, F., Spurkland, A., 2004. Genes in the HLA class I region may contribute to the HLA class II-associated genetic susceptibility to multiple sclerosis. Tissue Antigens 63, 237-247.

Hee, C.S., Gao, S., Miller, M.M., Goto, R., Ziegler, A., Daumke, O., Uchanska-Ziegler, B., 2009. Expression, purification and preliminary X-ray crystallographic analysis of the chicken $\mathrm{MHC}$ class I molecule YF1*7.1. Acta Cryst. F 65, 422-425.

Reche, P.A., Reinherz, E.L., 2003. Sequence variability analysis of human class I and class II MHC molecules: functional and structural correlates of amino acid polymorphisms. J. Mol. Biol. 331, 623641.

Reche, P.A., Zhang, H., Glutting, J.P., Reinherz, E.L., 2005. EPIMHC: a curated database of MHCbinding peptides for customized computational vaccinology. Bioinformatics 21, 2140-2141.

Rehm, A., Rohr, A., Seitz, C., Wonigeit, K., Ziegler, A., Uchanska-Ziegler, B., 2000. Structurally diverse forms of HLA-B27 molecules are displayed in vivo in a cell type-dependent manner. Hum. Immunol. 61, 408-418.

Ribic, A., Zhang, M., Schlumbohm, C., Matz-Rensing, K., Uchanska-Ziegler, B., Flugge, G., Zhang, W., Walter, L., Fuchs, E., 2010. Neuronal MHC class I molecules are involved in excitatory synaptic transmission at the hippocampal mossy fiber synapses of marmoset monkeys. Cell. Mol. Neurobiol. 30, 827-839.

Rolleke, U., Flugge, G., Plehm, S., Schlumbohm, C., Armstrong, V.W., Dressel, R., Uchanska-Ziegler, B., Ziegler, A., Fuchs, E., Czeh, B., Walter, L., 2006. Differential expression of major histocompatibility complex class I molecules in the brain of a New World monkey, the common marmoset (Callithrix jacchus). J. Neuroimmunol. 176, 39-50.

Ruckert, C., Fiorillo, M.T., Loll, B., Moretti, R., Biesiadka, J., Saenger, W., Ziegler, A., Sorrentino, R., Uchanska-Ziegler, B., 2006. Conformational dimorphism of selfpeptides and molecular mimicry in a disease-associated HLA-B27 subtype. J. Biol. Chem. 281, 2306-2316.

Rudolph, M.G., Stanfield, R.L., Wilson, I.A., 2006. How TCRs bind MHCs, peptides and coreceptors. Annu. Rev. Immunol. 24, 419-466.

Santos, P.S.C., Fust, G., Prohaszka, Z., Volz, A., Horton, R., Miretti, M., Yu, C.-Y., Beck, S., Uchanska-Ziegler, B., Ziegler, A., 2008. Association of smoking behavior with an odorant receptor allele telomeric to the human major histocompatibility complex. Genet. Test. 12, 481-486.

Santos, P.S.C., Uehara, C.J.S., Ziegler, A., Uchanska-Ziegler, B., Bicalho, M.G., 2010. Variation and linkage disequilibrium within odorant receptor gene clusters linked to the human major histocompatibility complex. Hum. Immunol. 71, 843-850. 
Schlosstein, L., Terasaki, P.I., Bluestone, R., Pearson, C.M., 1973. High association of an HL-A antigen, W27, with ankylosing spondylitis. N. Engl. J. Med. 288, 704-706.

Schumacher, T.N., Ploegh, H.L., 1994. Are MHC-bound peptides a nuisance for positive selection? Immunity 1, 721-723.

Siddle, H.V., Kreiss, A., Eldridge, M.D.B., Noonan, E., Clarke, C.J., Pyecroft, S., Woods, G.M., Belov, K., 2007. Transmission of a fatal clonal tumor by biting occurs due to depleted MHC diversity in a threatened carnivorous marsupial. Proc. Natl. Acad. Sci. U.S.A. 104, 16221-16226.

Siddle, H.V., Marzec, J., Cheng, Y., Jones, M., Belov, K., 2010. MHC gene copy number variation in Tasmanian devils: implications for the spread of a contagious cancer. Proc. Biol. Sci. 277, 2001-2006. Silver, M.L., Guo, H.C., Strominger, J.L., Wiley, D.C., 1992. Atomic structure of a human MHC molecule presenting an influenza virus peptide. Nature 360, 367-369.

Starr, T.K., Jameson, S.C., Hogquist, K.A., 2003. Positive and negative selection of T cells. Annu. Rev. Immunol. 21, 139-176.

Stewart-Jones, G.B., di Gleria, K., Kollnberger, S., McMichael, A.J., Jones, E.Y., Bowness, P., 2005. Crystal structures and KIR3DL1 recognition of three immunodominant viral peptides complexed to HLA-B*2705. Eur. J. Immunol. 35, 341-351.

Sundick, R.S., Bagchi, N., Brown, T.R., 1996. The obese strain chicken as a model for human Hashimoto's thyroiditis. Exp. Clin. Endocrinol. Diabetes 104 (Suppl. 3), 4-6.

Takahama, Y., Nitta, T., Mat Ripen, A., Nitta, S., Murata, S., Tanaka, K., 2010. Role of thymic cortexspecific self-peptides in positive selection of T cells. Semin. Immunol. 22, 287-293.

Taurog, J.D., 2009. Animal models of spondyloarthritis. Adv. Exp. Med. Biol. 649, 245-254.

Taurog, J.D., 2010. The role of HLA-B27 in spondyloarthritis. J. Rheumatol. 37, 2006-2016.

Thomas, G.P., Brown, M.A., 2010. Genetics and genomics of ankylosing spondylitis.

Immunol. Rev. 233, 162-180.

Tran, T.M., Dorris, M.L., Satumtira, N., Richardson, J.A., Hammer, R.E., Shang, J., Taurog, J.D., 2006. Additional human beta2-microglobulin curbs HLA-B27 misfolding and promotes arthritis and spondylitis without colitis in male HLA-B27-transgenic rats. Arthritis Rheum. 54, 1317-1327.

Tsuchiya, K., Kimura, A., Kondo, M., Nishimura, Y., Sasazuki, T., 2001. Combination of HLA-A and HLA class II alleles controls the susceptibility to rheumatoid arthritis. Tissue Antigens 58, 395-401. Tyzack, J.K., 2008. Dragging (and zooming and rotating) publication of 3D molecular structures into the 21st century. Trends Biochem. Sci. 33, 405-407.

Uchanska-Ziegler, B., Ziegler, A., 2003a. Ankylosing spondylitis: a_2m-deposition disease? Trends Immunol. 24, 73-76.

Uchanska-Ziegler, B., Ziegler, A., 2003b. Response to Xie and Yi: Ankylosing spondylitis:

a_2m-deposition disease? Trends Immunol. 24, 229-230.

Uchanska-Ziegler, B., Ziegler, A., 2007. On the reactivity of monoclonal antibodies specific for different forms of HLA class I molecules. Rheumatology (Oxford) 46, 555-556.

Uchanska-Ziegler, B., Ziegler, A., 2008. HLA-B27 transgenic rats, amyloid deposits, and spondyloarthropathies. Mod. Rheumatol. 18, 425-426.

Uchanska-Ziegler, B., Alexiev, U., Hillig, R., Hulsmeyer, M., Pohlmann, T., Saenger, W., Volz, A., Ziegler, A., 2006. X-ray crystallography and dynamic studies of HLAB* 2705 and $B^{*} 2709$ molecules complexed with the same peptide. In: Hansen, J.A., et al. (Eds.), Immunobiology of the Human MHC: Proceedings of the $13^{\text {th }}$ International Histocompatibility Workshop and Congress, vol. I. IHWG Press, Seattle, USA, pp. 138-147.

Urban, R.G., Chicz, R.M., Lane, W.S., Strominger, J.L., Rehm, A., Kenter, M.G.H., UytdeHaag, F.G.C.M., Ploegh, H.L., Uchanska-Ziegler, B., Ziegler, A., 1994. A subset of HLA-B27 molecules contains peptides much longer than nonamers. Proc. Natl. Acad. Sci. U.S.A. 91, 1534-1538. von Boehmer, H., 1994. Positive selection of lymphocytes. Cell 76, 219-228.

von Boehmer, H., Aifantis, I., Gounari, F., Azogui, O., Haughn, L., Apostolou, I., Jaeckel, E., Grassi, F., Klein, L., 2003. Thymic selection revisited: how essential is it? Immunol. Rev. 191, 62-78.

Wallny, H.J., Avila, D., Hunt, L.G., Powell, T.J., Riegert, P., Salomonsen, J., Skjødt, K., Vainio, O., Vilbois, F., Wiles, M.V., Kaufman, J., 2006. Peptide motifs of the single dominantly expressed class I molecule explain the striking MHC determined response to Rous sarcoma virus in chickens. Proc. Natl. Acad. Sci. U.S.A. 103, 1434-1439.

Winkler, K., Winter, A., Rueckert, C., Uchanska-Ziegler, B., Alexiev, U., 2007. Natural MHC class I polymorphism controls the pathway of peptide dissociation from HLA-B27 complexes. Biophys. J. 93, 2743-2755.

Woelfing, B., Traulsen, A., Milinski, M., Boehm, T., 2009. Does intra-individual major histocompatibility complex diversity keep a golden mean? Phil. Trans. R. Soc. B 364, 117-128.

Zawacka, A., Loll, B., Biesiadka, J., Saenger, W., Uchanska-Ziegler, B., Ziegler, A., 2005. X-ray diffraction analysis of crystals from the human major histocompatibility antigen HLA-B*2706 in complex with a viral peptide and with a self-peptide. Acta Cryst. F 61, 1097-1099. 
Ziegler, A., 1997. Biology of chromosome 6. DNA Sequence 8, 189-202.

Ziegler, A., 2003. Molekule des MHC und olfaktorische Rezeptoren: Mogliche Bedeutung im Rahmen der Reproduktion. J. Fertil. Reprod. 13, 14-18.

Ziegler, A., Pink, J.R.L., 1976. Chemical properties of two antigens controlled by the major histocompatibility complex of the chicken. J. Biol. Chem. 251, 5391-5396.

Ziegler, A., Ehlers, A., Forbes, S., Trowsdale, J., Uchanska-Ziegler, B., Volz, A., Younger, R., Beck, S., 2000. Polymorphic olfactory receptor genes and HLA loci constitute extended haplotypes. In: Kasahara, M. (Ed.), Major Histocompatibility Complex - Evolution, Structure, and Function. Springer Verlag, Tokyo, pp. 110-130.

Ziegler, A., Dohr, G., Uchanska-Ziegler, B., 2002. Possible roles for products of polymorphic MHC and linked olfactory receptor genes during selection processes in reproduction. Am. J. Reprod. Immunol. 48, 34-42.

Ziegler, A., Kentenich, H., Uchanska-Ziegler, B., 2005. Female choice and the MHC. Trends Immunol. 26, 496-502.

Ziegler, A., Dohr, G., Kentenich, H., Uchanska-Ziegler, B., 2006. Self-nonself discrimination and reproductive performance. In: Hansen, J.A., et al. (Eds.), Immunobiology of the Human MHC:

Proceedings of the 13th International Histocompatibility Workshop and Congress, vol. I. IHWG Press, Seattle, USA, pp. 1534-1538.

Ziegler, A., Coulie, P.G., Uchanska-Ziegler, B., 2007. Monoclonal and recombinant antibodies with T cell receptor-like reactivity. In: Dietel, M. (Ed.), Recent Results in Cancer Research - Targeted Therapies in Cancer, vol. 176. Springer Verlag, Heidelberg, pp. 229-242.

Ziegler, A., Faber, C., Mueller, S., Bartolomaeus, T., 2008. Systematic comparison and reconstruction of sea urchin (Echinoidea) internal anatomy: a novel approach using magnetic resonance imaging. BMC Biol. 6, 33.

Ziegler, A., Muller, C.A., Bockmann, R.A., Uchanska-Ziegler, B., 2009a. Low-affinity peptides and Tcell selection. Trends Immunol. 30, 53-60.

Ziegler, A., Loll, B., Misselwitz, R., Uchanska-Ziegler, B., 2009b. Implications of structural and thermodynamic studies of HLA-B27 subtypes exhibiting differential association with ankylosing spondylitis. Adv. Exp. Med. Biol. 649, 177-195.

Ziegler, A., Santos, P.S.C., Kellermann, T., Uchanska-Ziegler, B., 2010a. Self/nonself perception, reproduction, and the extended MHC. Self/Nonself 1, 176-191.

Ziegler, A., Ogurreck, M., Beckmann, F., Steinke, T., Prohaska, S., Ziegler, A., 2010b. Opportunities and challenges for digital morphology. Biol. Direct 5, 45.

Ziegler, A., Mooi, R., Rolet, G., de Ridder, C., 2010c. Origin and evolutionary plasticity of the gastric caecum in sea urchins (Echinodermata: Echinoidea). BMC Evol. Biol. 10, 313.

Ziegler, A., Mietchen, D., Faber, C., von Hausen, W., Schobel, C., Sellerer, M., Ziegler, A., 2011. Effectively incorporating selected multimedia content into medical publications. BMC Med. 9, 17 


\section{Tables and Figures}

Table 1. Peptide-HLA class I complexes analysed.

\begin{tabular}{|c|c|c|c|c|c|c|c|}
\hline \multirow[t]{2}{*}{ Peptide } & \multirow{2}{*}{$\begin{array}{l}\text { Origin of } \\
\text { peptide }\end{array}$} & \multirow[t]{2}{*}{ Sequence } & \multicolumn{2}{|c|}{ HLA-B27 subtypea } & \multirow{2}{*}{$\begin{array}{l}\text { Other HLA } \\
\text { molecule }\end{array}$} & \multirow{2}{*}{$\begin{array}{l}\text { Resolution } \\
(\dot{A})\end{array}$} & \multirow[t]{2}{*}{ Reference } \\
\hline & & & $B * 27: 05$ & $B * 27: 09$ & & & \\
\hline $\mathrm{mg}$ & Model & GRAAAAAIAK & $\begin{array}{l}X, T, F \\
M\end{array}$ & $\begin{array}{l}X, T, F, \\
M\end{array}$ & & $2.101 .09^{1}$ & $\begin{array}{l}a, b, c, d, e, \\
f, g\end{array}$ \\
\hline s10R & Modified self & RRLLRGHNQY & $T$ & $X, T$ & & 1.90 & $b, g$ \\
\hline$s 10 G$ & Modified self & GRLLRGHNQY & $T$ & $\mathrm{~T}$ & & & $b, g$ \\
\hline PVIPR & Self & RRKẄRRw'iHL & $X, I, F$ & $X, 1, F$ & & $1.47 / 2.20$ & $g, h, i, j, k$ \\
\hline pLMP2 & Viral & RRRW'RRLTV & $X, I, F$ & $X, 1, F$ & & $1.55 M .72$ & $9, j, 1$ \\
\hline pLMP2 & Viral & RRRWRRLTV & & & $B^{\star} 14: 02^{b}$ & 2.55 & $m, n$ \\
\hline TIS & Self & RRLPIFSRL & $X, T, I, F$ & $X, T, I, F$ & & $2.27 / 2.10$ & $f, j, o$ \\
\hline pGR & Self & RRRIMHRW'WL & $x$ & $x$ & & $1.50 M .10$ & $f, p$ \\
\hline pVIPR-U5 & Modified self & RRKWứU'WHLc & $x, 1$ & $x, 1$ & & $1.79 M .86$ & $k, q$ \\
\hline pCatA & Self & IRAAPPPLF & $x$ & $x$ & & $1.85 M .80$ & $n$ \\
\hline pCat $\mathrm{A}$ & Self & IRAAPPPLF & & & $B^{\star} 14: 02^{b}$ & 1.86 & $m, n$ \\
\hline $\mathrm{pCAC}$ & Self & SRR'MRRMUNR & $x$ & & & 1.94 & $p, r$ \\
\hline nef & Viral & VPLRPMTY & & & $B^{\star} 35: 01^{b}$ & $3.2 / 2.59$ & $s$ \\
\hline$M A G E-A 4$ & Self & GVYDGREHTV & & & $\mathrm{A}^{*} 02: 01^{\mathrm{b}}$ & 1.4 & $t$ \\
\hline MAGE-A1 & Self & EADPTGHSY & & & $\mathrm{A}^{*} 01: 01^{\mathrm{b} A \mathrm{~d}}$ & 2.15 & $u, v$ \\
\hline MAGE-A1 & Self & EADPTGHSY & & & $A^{*} 01: 01^{b}=$ & 1.80 & v \\
\hline
\end{tabular}

References: a, Hülsmeyer et al. (2002); b, Hilliget al. (2004); c, Pöhlmann et al. (2004); d, Uchanska-Ziegler et al. (2006); e, Wuinkler et al. (2007); f, Ziegler et al. (2009a); g, Ziegler et al. (2009b); h, Hülsmeyer et al. (2004); i, Fabian et al. (2008); j, Fabian et al. (2010); k, Fabian et al. (2011); I, Fiorillo et al. (2005); m, Kumar et al. (2007); n, Kumar et al. (2009a); o, Hülsmeyer et al. (2005b); p, Rückert et al. (2006); q, Beltrami et al. (2008); r, Loll et al. (2011); s, Menssen et al. (1999); t, Hillig et al. (2001); u, Hülsmeyer et al. (2005a); v, Kumar et al. (2009b).

a The experimental procedures include $X, X_{\text {-ray }}$ crystallography; $T$, thermodynamic measurements; $F$, fluorescence spectroscopy: $M$, molecular dynamics simulations; 1 , isotope-edited IR spectroscopy.

b X-aycrystallography only.

c $\quad \mathrm{U}=$ citrulline.

d MAGE-A, $1+H L A-A^{*} 01: 01$ in complex with the Fab-fragment Fab-Hyb3.

e MAGE-A 1 1 HLA-A $01: 01$ without Fab+Hyb3.

f $X / N$ : First walue, $B^{\star} 27: 05$, second value, $B^{\wedge} 27: 09$.

g Two sets of diffraction data were obtained for the nef $-\mathrm{B}^{\star} 3501$ complex. 
Figure 1. Peptides bound to $B^{\star} 27: 05$ and $B^{\star} 27: 09$. (A) View of the m9-HLA-B27 complex from the top, looking into the binding groove. The $\alpha 1-$ and $\alpha 2$-helices are indicated. The orange sphere depicts the position of $\mathrm{HC}$ residue 116. (B-G) Side views looking from the a2-helices (omitted) towards the a1helices. The $m 9$ peptide bound to $B^{\star} 27: 05(B)$ and $B^{\star} 27: 09(C)$ is shown in green. Salt bridges are shown as red dashed lines. The interaction details are shown in Fig. 5. The self-peptide TIS (red) is bound in a conformation which is very similar in $B^{\star} 27: 05(D)$ and $B^{\star 2} 27: 09(E)$. The self-peptide pCatA (blue) is displayed in a nearly identical conformation by the two subtypes $B^{\star} 27: 05(F)$ and $B^{\star 2} 27: 09(G)$ as well.

A
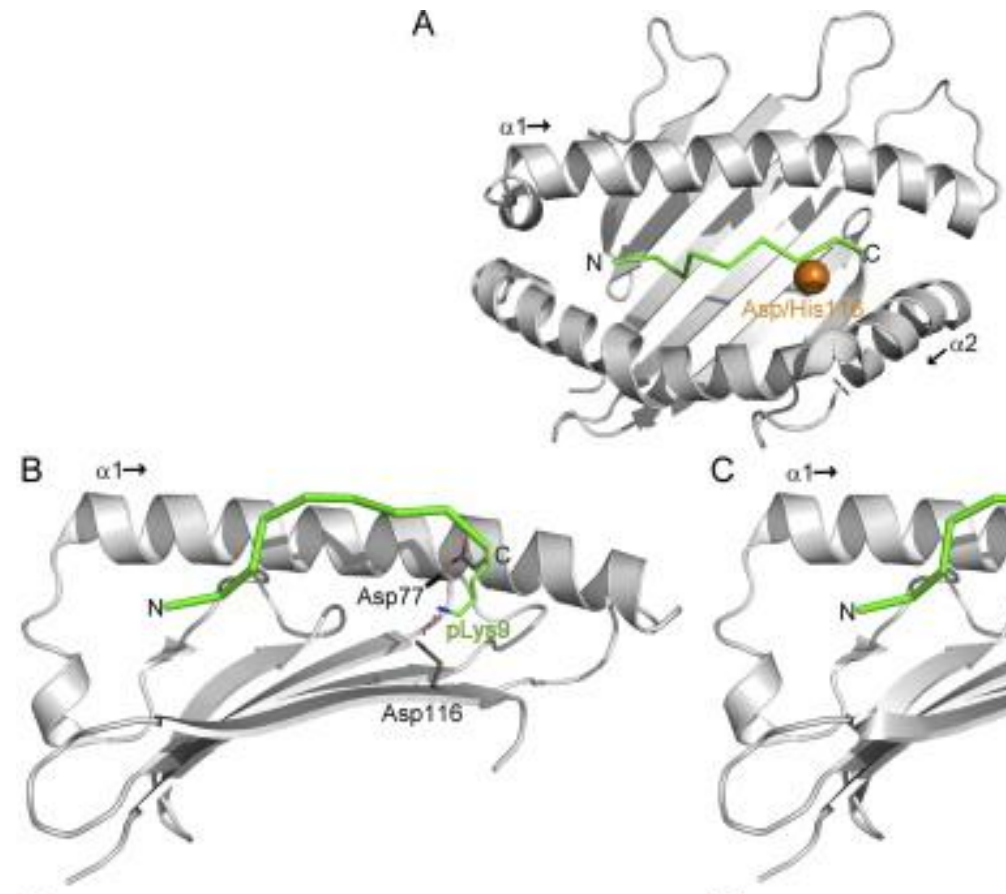

C $a 1 \rightarrow$

$\mathrm{D}$

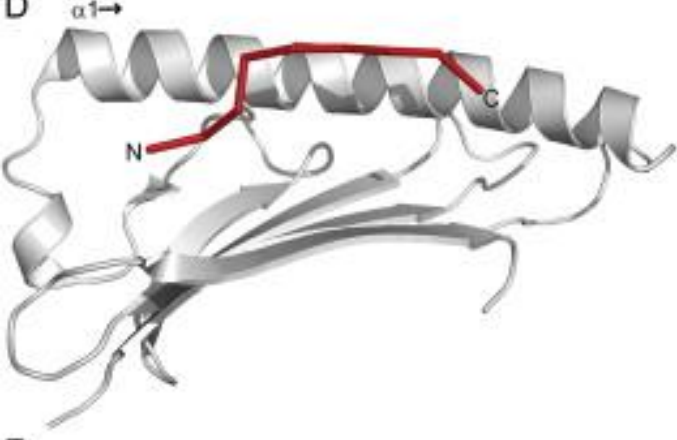

$F_{\alpha 1 \rightarrow}$

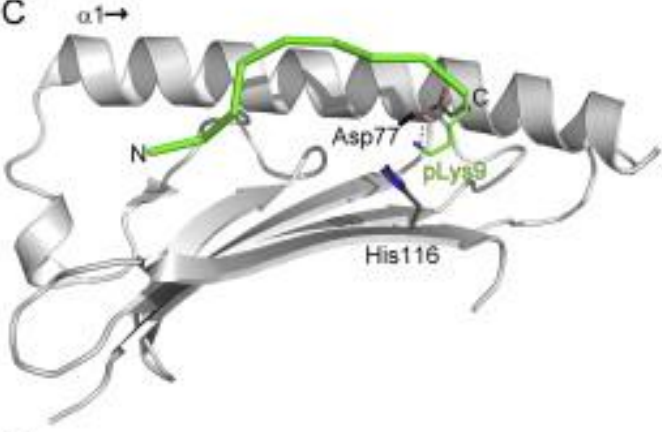

E
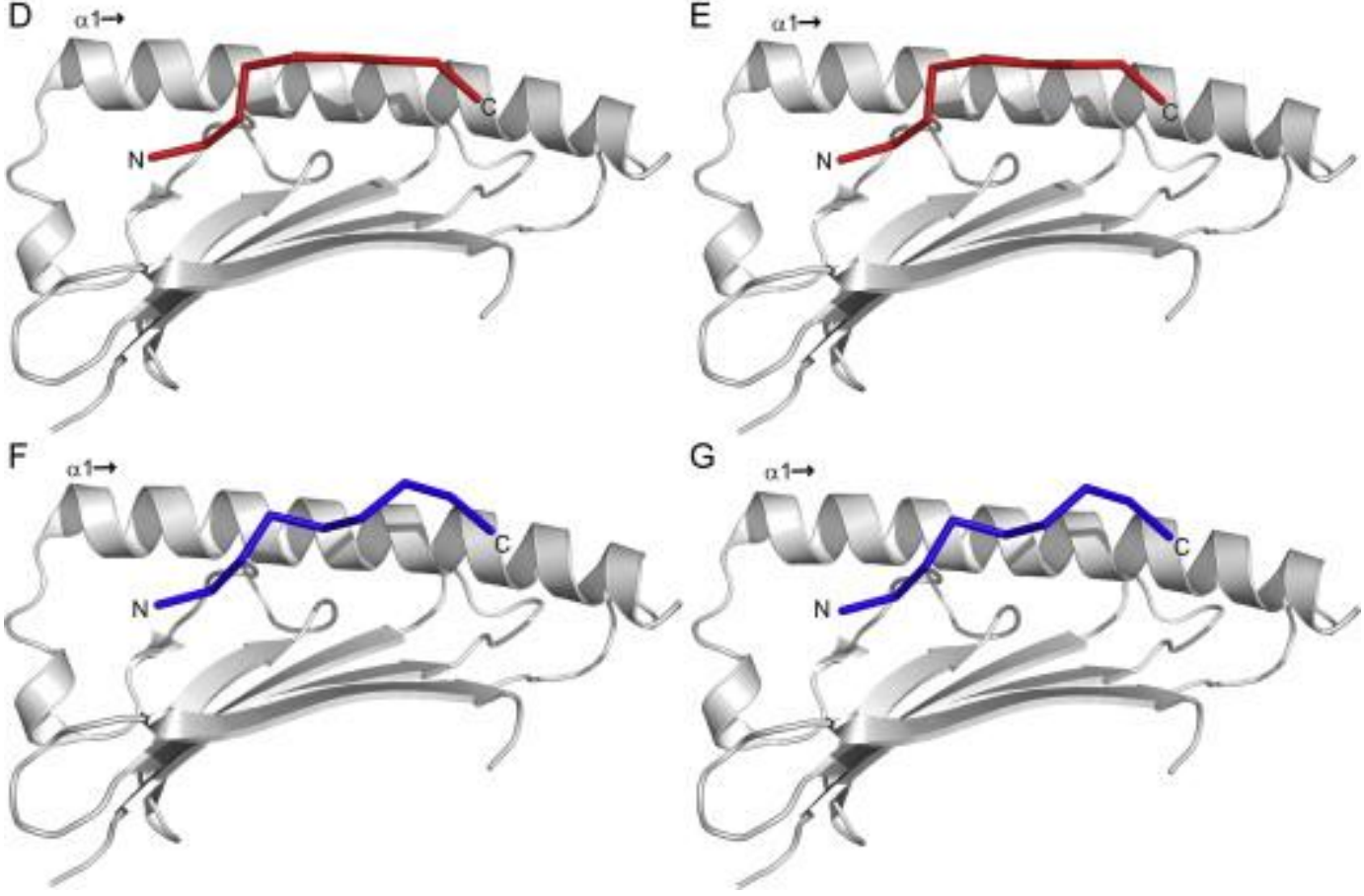

G

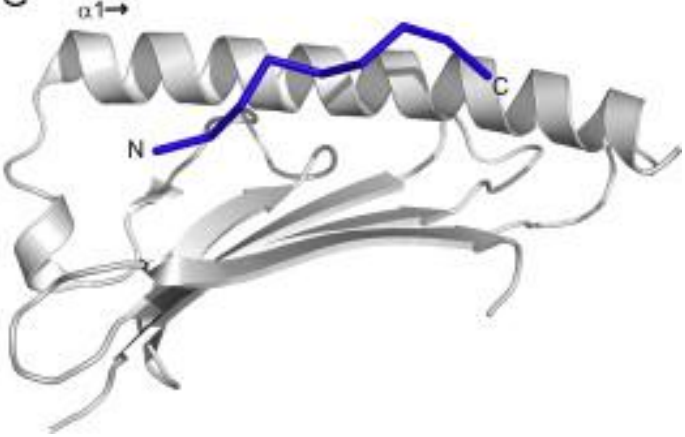


Figure 2. The influence of residue 116 polymorphism on peptide conformation. (A-G) Side views looking from the a2-helices (omitted) onto the a1-helices. Salt bridges or hydrogen bonds (only in F) are shown as red dashed lines. The viral peptide pLMP2 (light blue) is bound in a non-canonical conformation to $B^{*} 27: 05(A)$, but in a canonical conformation to $B^{*} 27: 09$ (B). pArg5 of pLMP2 contacts Asp 116 of the $B^{\star} 27: 05$ via salt bridges, but comparable contacts are not possible in $B^{\star 2} 27: 09$ due to His 116. The self-peptide pVIPR is bound in a dual conformation (canonical, cyan and non-canonical, magenta) to $B^{\star 27: 05}(C)$ while only the canonical conformation is observed in $B^{\star} 27: 09$ (D). The citrullinated pVIPR-U5 peptide (brown) is bound canonically to $B^{*} 27: 05(E)$, but non-canonically to $B^{\star} 27: 09(F)$, because of a hydrogen bond between pU and His 116 of the $B^{\star} 27: 09 \mathrm{HC}$. (G) pArg9 of the PCAC peptide (orange) is preferred over DArg for the interaction with Asp 116 when complexed with $B^{\star} 27: 05$. The interaction details are shown in Fig. 5.

A

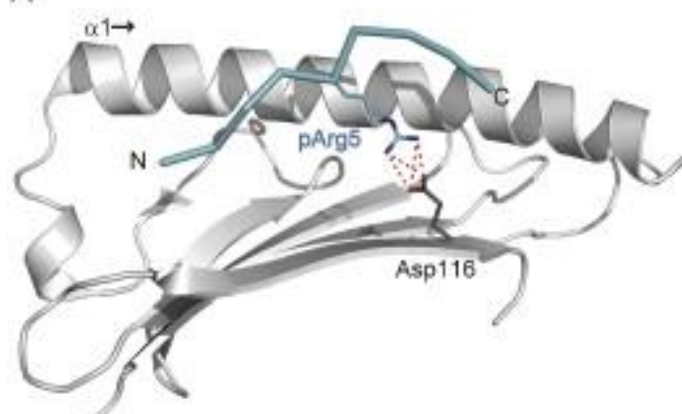

C

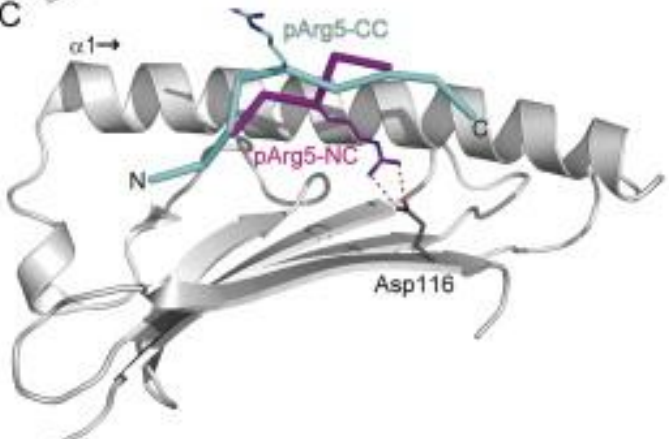

B

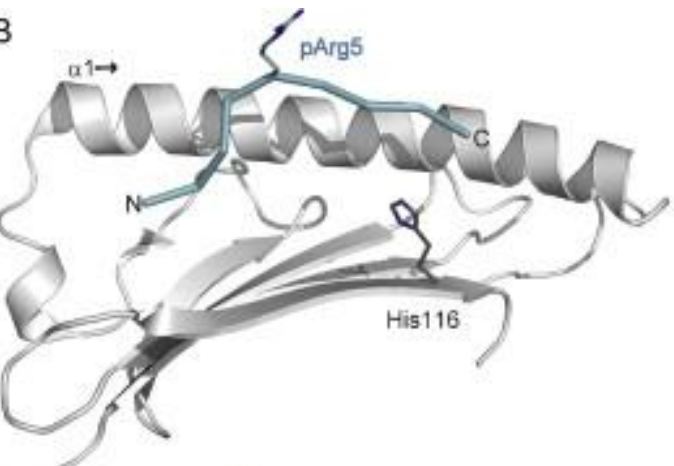

D

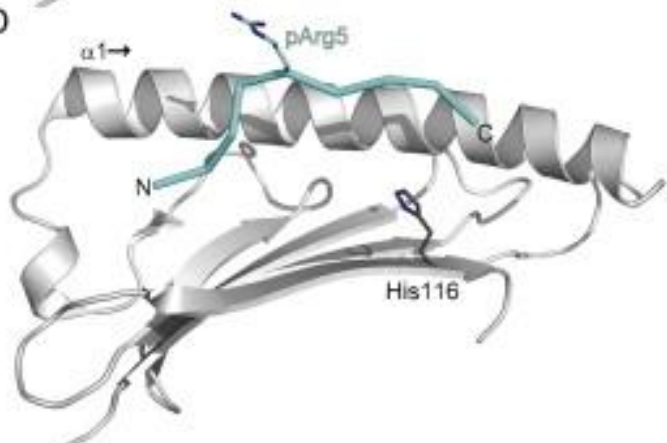

E
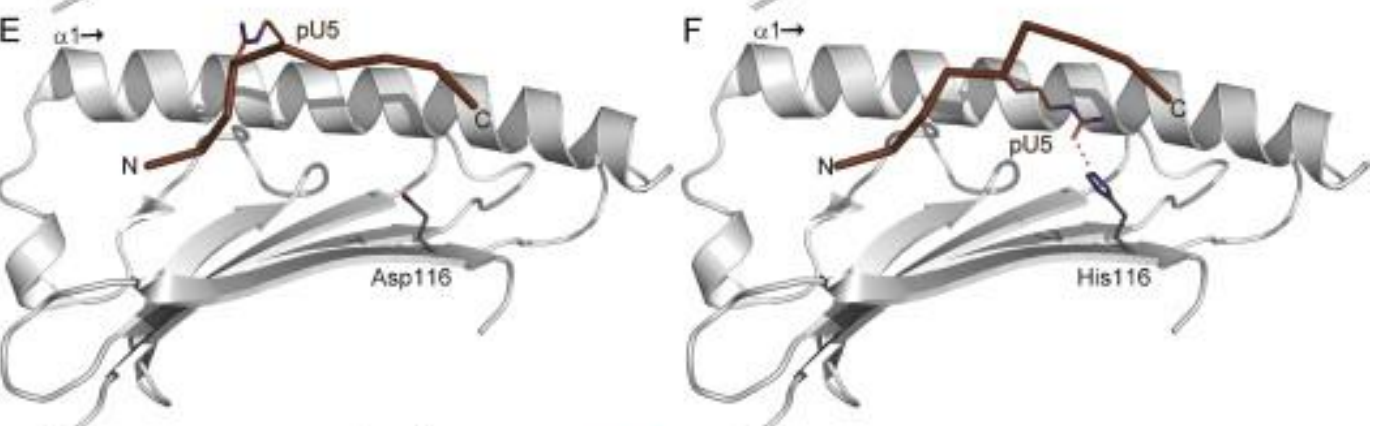

G

G $\quad \alpha 1 \rightarrow$

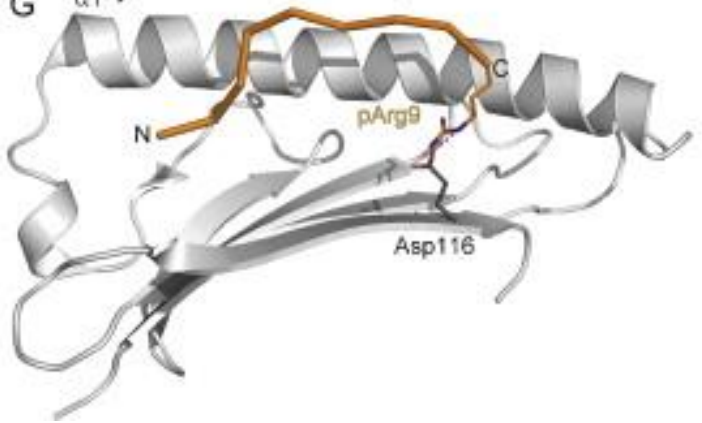


Figure 3. $H / D$ exchange characteristics analysed by $B^{\star} 27: 05 / B^{\star} 27: 09$ IR difference spectra. (Left panel) IR difference spectra obtained by subtracting the spectrum of $p$ VIPR-B ${ }^{*} 27: 05 /{ }^{13} \mathrm{C} \beta_{2} \mathrm{~m}$ from that of $p$ VIPR-B ${ }^{\star} 27: 09 /{ }^{13} \mathrm{C} \beta_{2} \mathrm{~m}$. (Right panel) IR difference spectra obtained by subtracting the spectrum of TIS-B ${ }^{\star} 27: 05 /{ }^{13} \mathrm{C} \beta_{2} \mathrm{~m}$ from that of TIS-B*27:09/ $/{ }^{13} \mathrm{C} \beta_{2} \mathrm{~m}$. The positive feature at $\sim 1545 \mathrm{~cm}^{-1}(\mathrm{~N}-\mathrm{H})$ and a corresponding negative feature at $\sim 1445 \mathrm{~cm}^{-1}(\mathrm{~N}-\mathrm{D})$ indicate a lower degree of hydrogen/deuterium exchange of some amide groups of the $B^{\star} 27: 09 \mathrm{HC}$ compared with the $\mathrm{B}^{\star 2} 27: 05 \mathrm{HC}$ at temperatures between 15 and $55^{\circ} \mathrm{C}$. The first spectrum of each sample $\left(\right.$ at $\left.15^{\circ} \mathrm{C}\right)$ was obtained $1 \mathrm{~h}$ after transfer into $\mathrm{D}_{2} \mathrm{O}$ buffer. For further explanations, please refer to [Fabian et al., 2008], [Fabian et al., 2010] and [Fabian et al., 2011].

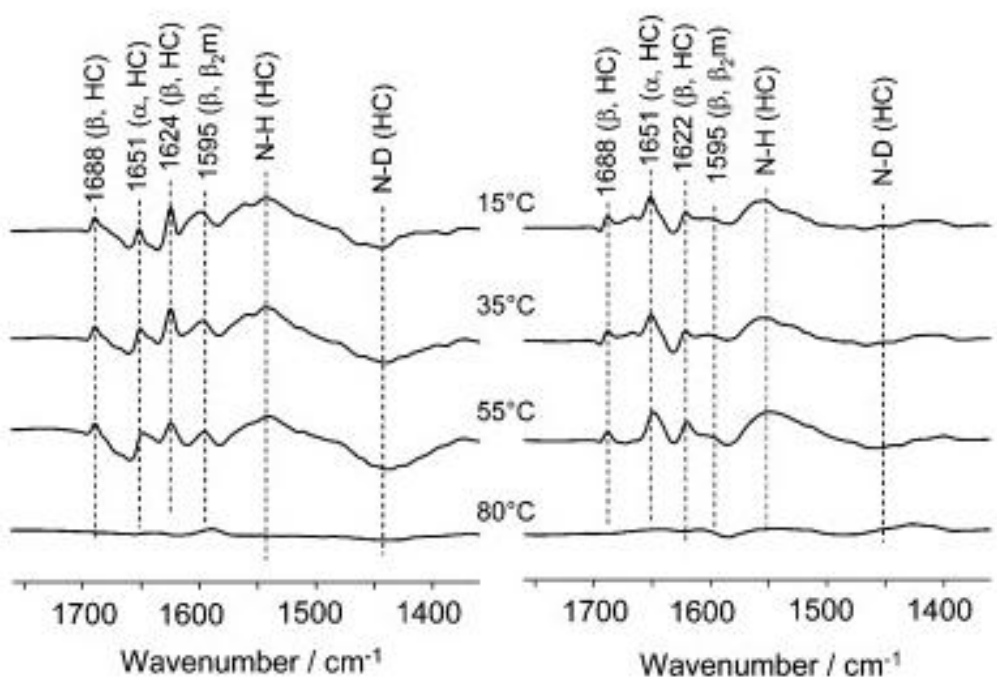

Figure 4. Amino acid sequence alignment of the $\alpha 1$ - and $\alpha 2$-domains (residues 1-180) of selected HLA-A and -B subtypes. Polymorphic residues are indicated in red. Residues contributing to $F$ pocket architecture in $B^{*} 27: 05, A^{*} 11: 01$, or $A^{*} 68: 01$ by interacting with the $C$-terminus of a peptide are marked with "F", see Fig. 5 for the respective contacts. Sequences were obtained from the IMGT/HLA database (http://www.ebi.ac.uk/imgt/hla/).

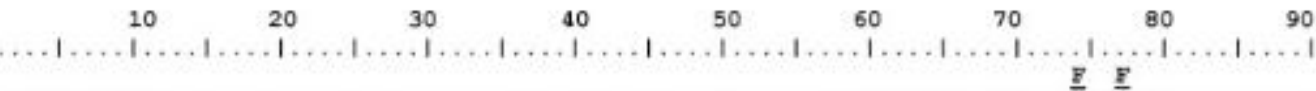

HLA-A*02:01 GSHSMRYFFTSVSRPGRGEPRFIAVGYVDDTEFVFDSDAASQRMEPFAFWIEQEGPEYWDGE TRKVKAHSQTHRVDLGTL.RGYYNQSEA HLA-A*03:01 GSHSMRYFITSVSRPGEGEPRFIAVGYVDD TOFVPFDSDAASORME PRAPWIEOEGPEYWDOE TROVKAOSOTDRVDLFTLAGYYNOSEA HIA-A*11:01 GSHSMRYFYTSVSRPGRGEPRFIAVGYVDOTQFVRFDSDAASQRMEPRAWWIEQEGPEYWDQB TRIVVKAOSQTDRVDLOTL.RGYYMQSED HLA-A*31:01 GSHSMRYFITSVSRPGRGEPRFIAVGYVDDTOFVRFDSDARSRMRPRAFWIEQBRPEYWDQRTRAVKAHSQIDRVDLGTLRGYYNOSEA HLA-A $\$ 33: 01$ GSHSMRYFTTSVSRPGRGEPRFIAVGYVDTQFVRFDSDAASQRMEPRARWIEQEGPEYWDFATTOKVKAHSQTDRVDLGTLRGYYNQSEA HLA-A*68:01 GSHSMRYFYTSVSRPGRGEPRFIAVGYVDOTOFVRFDSDAASQRMEPRAFWIEQSGPEYWDFAVTRIVKAOSOTDRVDLSTLRGYYNOSEA

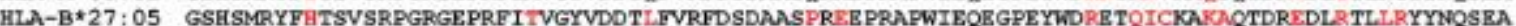
HLA-B*27:09 GSHSMRYFHSVSRPGRGEPRFITVGYVDTLFVRPDSDAASPREEPRAPWIEQEGPEYWDRB TQICKAKACTDREDLRTLTRYYNQSBA

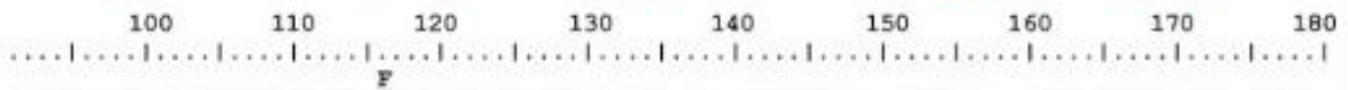

HLA-A*02:01 GSHTVQRYGCDVGSDWRFLRGYMQYYYYDGKYYIALCEDLRSWTAADMAAQTTKHKWEAAIVAEQLRAYLEGTCVEWLRRYLENGKETLQ HLA-A*03:01 GSHTIQDTYCDVGSDGRFLRGYRQDAYDGKDYIAT2NEDLRSWTAADMAAQITKKRKEEAAHEAEQLRAYLDGTCVEWLRRYLENGKETLQ

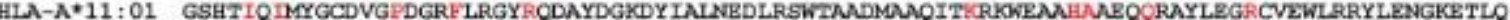
HIA-A *31:01 GSHTIOYMYGCDVGSDGRFLRGYCODAYDGKDYIAUNEDLRSWTAADMAAOTTORKWEAARVZRQLRAYLEGTCVEWLRRYLENGKETLO HLA-A*33;01 GSHTIQMYGCDVGSDGRFLRGYCODAYDGKDY LAL_NBDLRSWTAADMAAOTTORKWEAARVABQLRAYLEGTCVEWLRRHLENGKETLO

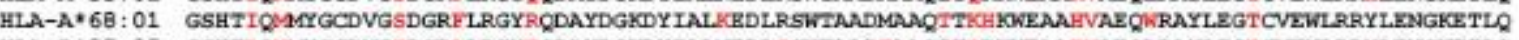
HLA-B*27:05 GSHTLQNYYGCDVGPDGRLLRGYBCDAYDGKDYIALIBDLSSWTAADTAAQITORKWEAARVABQLRAYLEGECVEWLRRYLENGKETLO HLA-B*27:09 GSHTLQNOMGCDVGPDGRLLRGYHQHAYDGKCYIALNEDLSSWTAADTAAQITQRKGEAARVAEQLRAYLEGECVEWL.RRYLENGKETLQ 
Figure 5. Peptide C-terminal contacts in the F pocket. (A-E) Side views looking from the a2-helices (omitted) onto the $\alpha 1$-helices. Salt bridges are shown as black dashed lines. The $\mathrm{m} 9$ peptide is bound to $B^{\star} 27: 05(A)$ and $B^{\star} 27: 09(B)$, the pCAC peptide is bound to $B^{\star} 27: 05(C)$, the SNP peptide is bound to $A^{*} 11: 01(D)$, and the pDP peptide is bound to $A^{*} 68: 01(E)$. An interactive three-dimensional (3D) figure is embedded into this figure (see online Supplementary material, Fig. S1) which can be activated by clicking anywhere on the image. All components are listed in the Model Tree on the left panel and each component can be shown/hidden by checking on the boxes. Preset views are given below the Model Tree with their designations and a "tour" can be accessed by clicking onto the green arrows above the preset view panel. Each model/view can be manipulated (rotated, panned, zoomed, etc.) using the tools available in the toolbar or the contextual menu. The 3D function can be terminated by right-clicking anywhere onto the model and choosing "Disable 3D". A full description of the manipulative possibilities has been provided by Tyzack (2008), while a detailed description of the production of such interactive, PDF-embedded figures is available in Kumar et al. (2010).

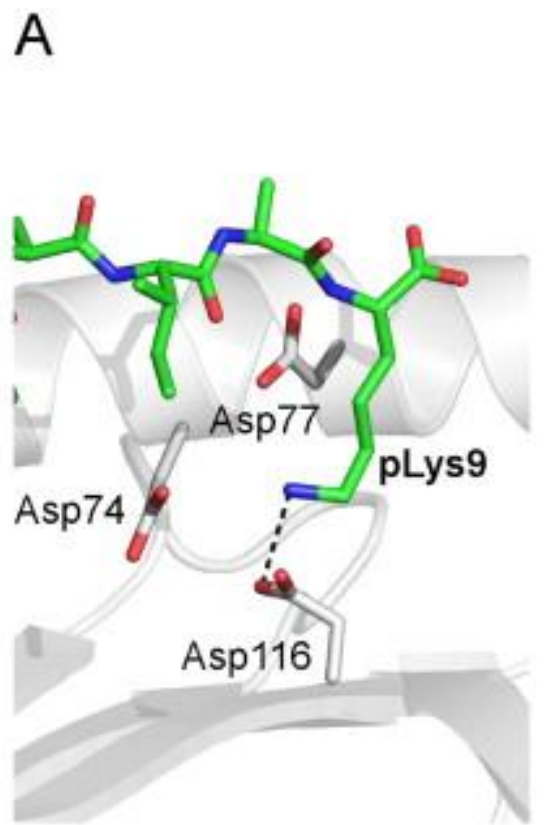

D

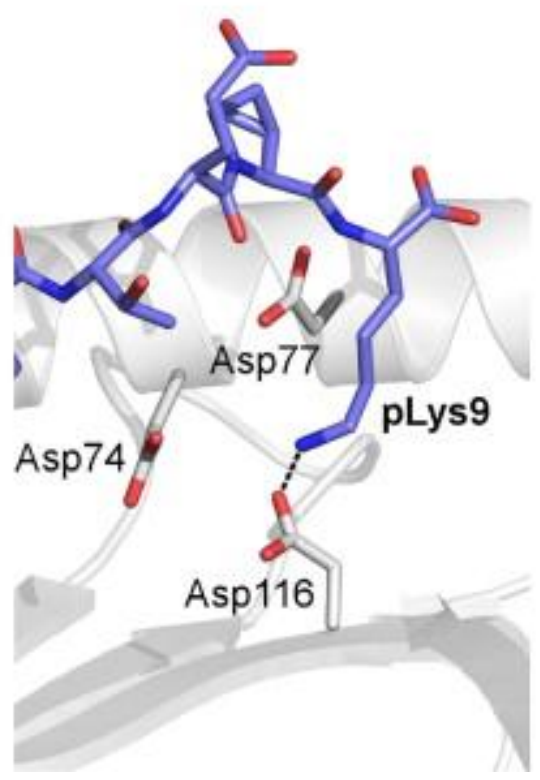

B

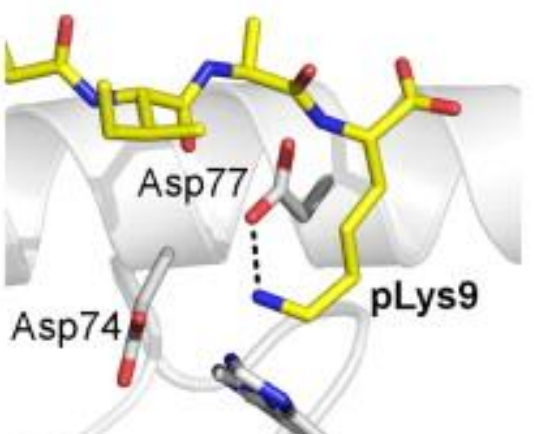

His 116

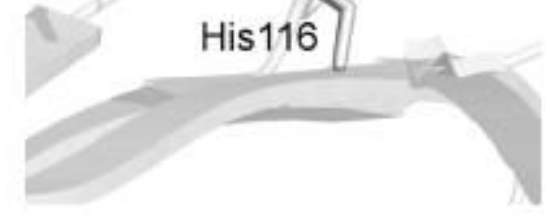

C

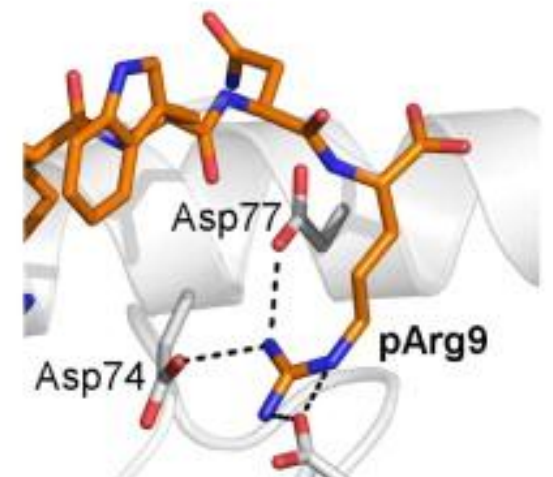

Asp116

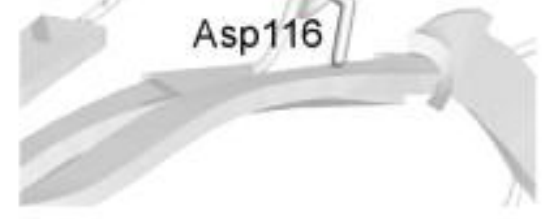

$E$

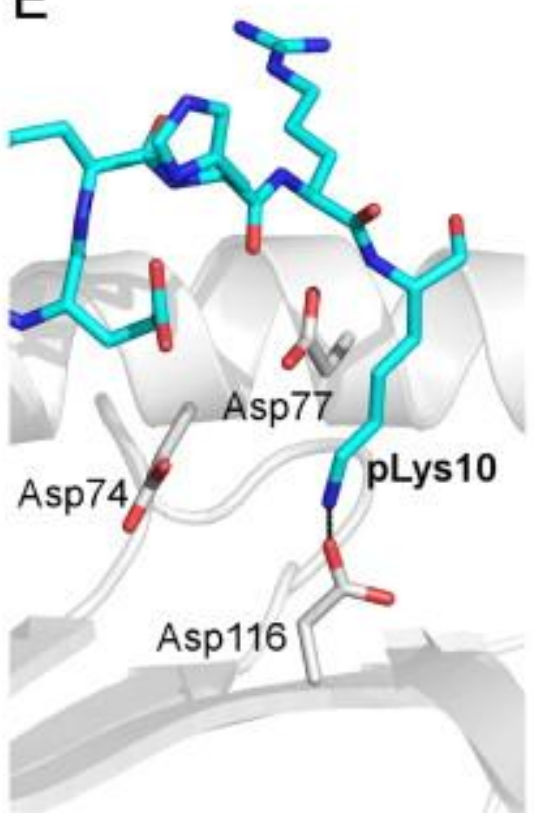

